\title{
Tension and Bending Testing of an Integral T-Cap for Stitched Composite Airframe Joints
}

\author{
Andrew E. Lovejoy ${ }^{1}$ and Frank A. Leone, Jr. ${ }^{2}$ \\ NASA Langley Research Center, Hampton, Virginia, 23681
}

\begin{abstract}
The Pultruded Rod Stitched Efficient Unitized Structure (PRSEUS) is a structural concept that was developed by The Boeing Company to address the complex structural design aspects associated with a pressurized hybrid wing body aircraft configuration. An important design feature required for assembly is the integrally stitched T-cap, which provides connectivity of the corner (orthogonal) joint between adjacent panels. A series of tests were conducted on $T$-cap test articles, with and without a rod stiffener penetrating the T-cap web, under tension (pull-off) and bending loads. Three designs were tested, including the baseline design used in large-scale test articles. The baseline had only the manufacturing stitch row adjacent to the fillet at the base of the T-cap web. Two new designs added stitching rows to the $T$-cap web at either 0.5 - or 1.0 -inch spacing along the height of the web. Testing was conducted at NASA Langley Research Center to determine the behavior of the T-cap region resulting from the applied loading. Results show that stitching arrests the initial delamination failures so that the maximum strength capability exceeds the load at which the initial delaminations develop. However, it was seen that the added web stitching had very little effect on the initial delamination failure load, but actually decreased the initial delamination failure load for tension loading of test articles without a stiffener passing through the web. Additionally, the added web stitching only increased the maximum load capability by between $1 \%$ and $12.5 \%$. The presence of the stiffener, however, did increase the initial and maximum loads for both tension and bending loading as compared to the stringerless baseline design. Based on the results of the few samples tested, the additional stitching in the T-cap web showed little advantage over the baseline design in terms of structural failure at the T-cap web/skin junction for the current test articles.
\end{abstract}

\section{Introduction}

$\mathrm{T}$ HE Pultruded Rod Stitched Efficient Unitized Structure (PRSEUS) ${ }^{1}$ is a structural concept that was developed by The Boeing Company (Boeing) to address the complex structural design aspects associated with a pressurized hybrid wing body (HWB) aircraft configuration as shown in Fig. 1. The HWB has long been a focus of the NASA Environmentally Responsible Aviation (ERA) Project, with structures development primarily addressing the pressurized, non-circular fuselage portion of the HWB. PRSEUS is an integral structural concept whereby skins, frames, stringers and tear straps are all stitched together, then infused and cured in an out-of-autoclave process. Shown in Fig. 2 is the PRSEUS concept as it has been applied to pressurized HWB fuselage structure. The concept has evolved out of stitching technology development from several NASA-Boeing and AFRL-Boeing programs starting in the 1990's. ${ }^{2-5}$ Stitching provides through-the-thickness reinforcement, and results in a unitized structure that can have damage arresting capability. The key to the PRSEUS concept is the pre-cured, pultruded rod that is contained within the stringer wrap plies and which passes through the frames, providing an uninterrupted load path. At the same time, the full depth frame stiffener is also continuous, except for the keyhole through which the stringer passes, providing an uninterrupted load path in the direction perpendicular to the stringer. These efficient structural stiffening members provide the majority of the panel stiffness, permitting the use of minimum skin thickness for many applications.

\footnotetext{
${ }^{1}$ Research Aerospace Engineer, Structural Mechanics and Concepts Branch, 8 West Taylor Street, Mail Stop 190, Associate Fellow AIAA.

${ }^{2}$ Research Aerospace Engineer, Structural Mechanics and Concepts Branch, 8 West Taylor Street, Mail Stop 190, Senior Member AIAA.
} 


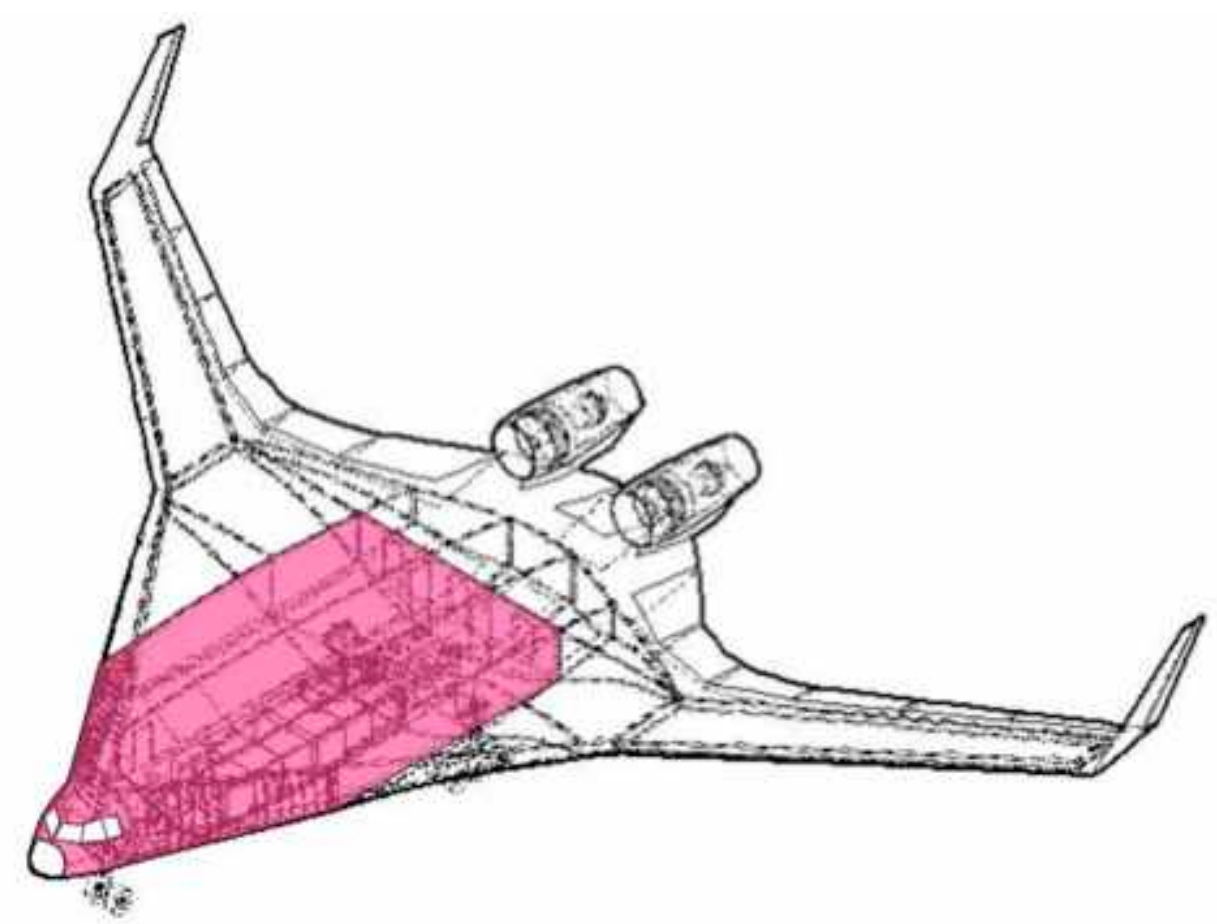

Figure 1. Typical pressurized portion of a HWB aircraft concept, shown as red shaded area.

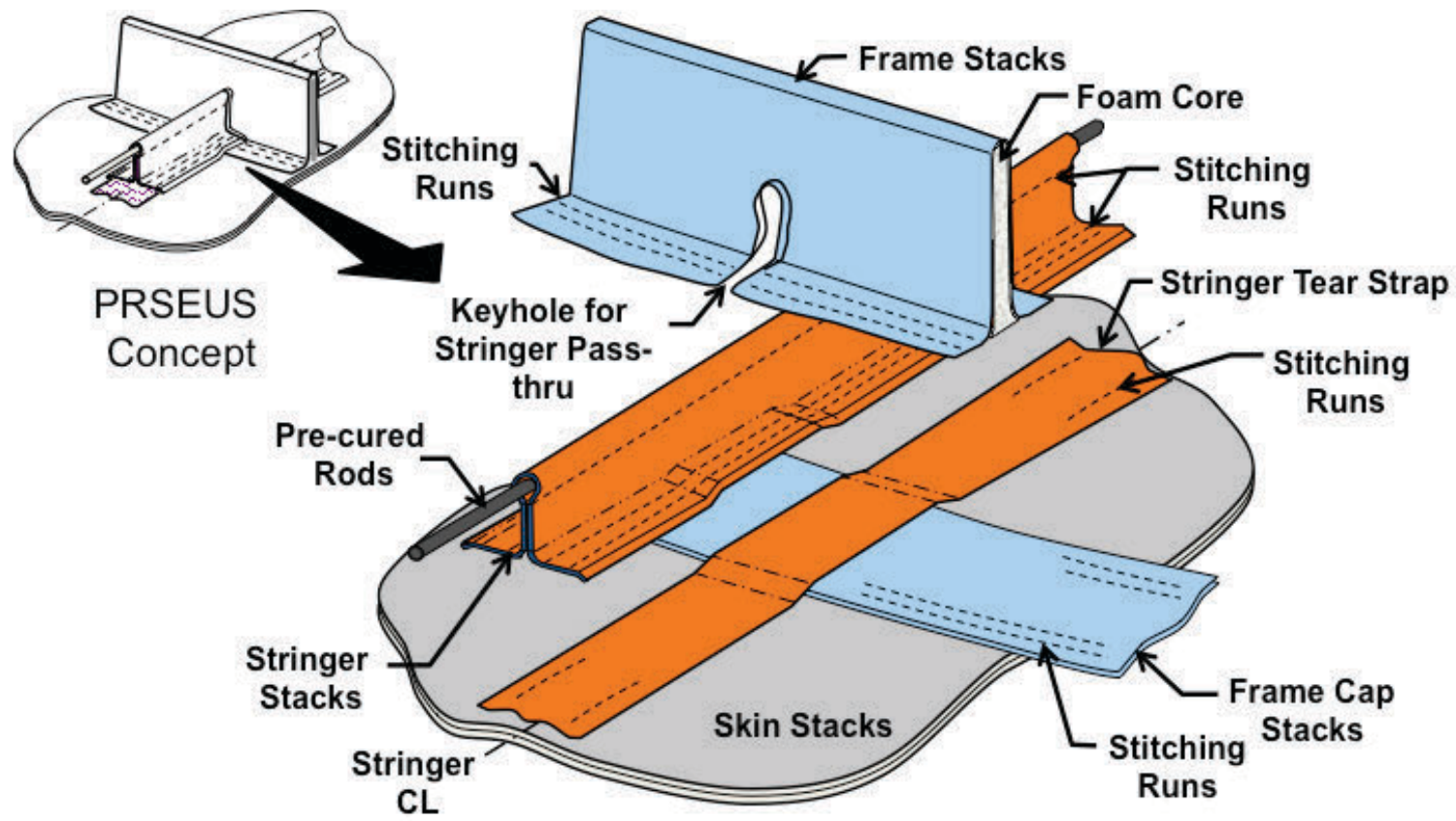

Figure 2. Typical PRSEUS concept.

Throughout ERA, the building block approach has been used to design, analyze, build, and test HWB PRSEUS structural components leading to an $80 \%$ scale center portion of the HWB as shown in Fig. 3 (identified as the Multi-Bay Pressure Box (MBB) in the lower right portion of the figure). The MBB began testing in the NASA Langley Research Center (LaRC) Combined Loads Test System (COLTS) Facility ${ }^{6,7}$ in April 2015, and has been subjected to a series of load conditions. A photograph of the test article between the platens in the COLTS Facility 
and a graphical representation of the COLTS arrangement is shown in Fig. 4. The platens were rotated to apply mechanical loads to the test article. Five loading conditions were applied to the pristine MBB in a series of experiments under design limit load (DLL) and then design ultimate load (DUL) levels. These loading conditions are 1) an internal pressure load alone where DUL is $18.4 \mathrm{psi}$; 2) a load simulating a 2.5 -g bending condition which subjects the crown panel to compressive loads; 3 ) a $-1-\mathrm{g}$ bending condition which subjects the crown panel to tensile loads; 4) a combination of pressure and -1-g bending; and 5) a combination of pressure and 2.5-g bending.

An important design feature of the MBB is the integrally stitched T-cap, shown in Fig. 5, which provides connectivity at the corner joint between orthogonal panels, and enables determinant assembly. The integrally stitched T-cap was introduced in the composite semi-span test article that was tested at LaRC as part of the Advanced Subsonic Technology (AST) Wing Program. ${ }^{8-10}$ In Fig. 5, the identifiers T1 and T2 indicate the T-cap locations, and S1 and S11 indicate the locations of the first and last stringer locations. The T-cap is a blade configuration having a web that is attached to the adjacent panel, with flanges integrated into the skin region of the panel as shown in Fig. 6. The stacks that comprise the web are those that wrap at the base of the web to make up the outer and inner flanges. Inner refers to the pressurized side (pressurized portion interior), and outer refers to the unpressurized side (exterior), of the T-cap web. Filler material, referred to as the noodle, was inserted into the cavity created by the flange wrap radii and the skin stacks. The baseline T-cap has stitches at the locations indicated by the dashed light green lines shown in Fig. 6. When incorporated into the final structure, the integral T-cap web height is trimmed according to the fastener pattern to reduce weight. A close-up view showing the effect of trimming on the integral T-cap joining the MBB crown to the upper bulkhead is shown in Fig. 7, with the integral T-cap being incorporated into the crown panel. T-caps were first integrated and tested for PRSEUS panels in a pressure cube that was tested at the COLTS Facility. ${ }^{11,12}$ The cube was loaded with internal pressure, which resulted in the T-caps being both pulled in tension and bent about the base. During testing of the pressure cube, between pressure sequences, areas of delamination were detected in the region of the T-cap base and radii (web/skin interface) ${ }^{13}$ In order to better characterize the response and performance of the T-cap, this paper presents test results for T-cap tension and bending tests.

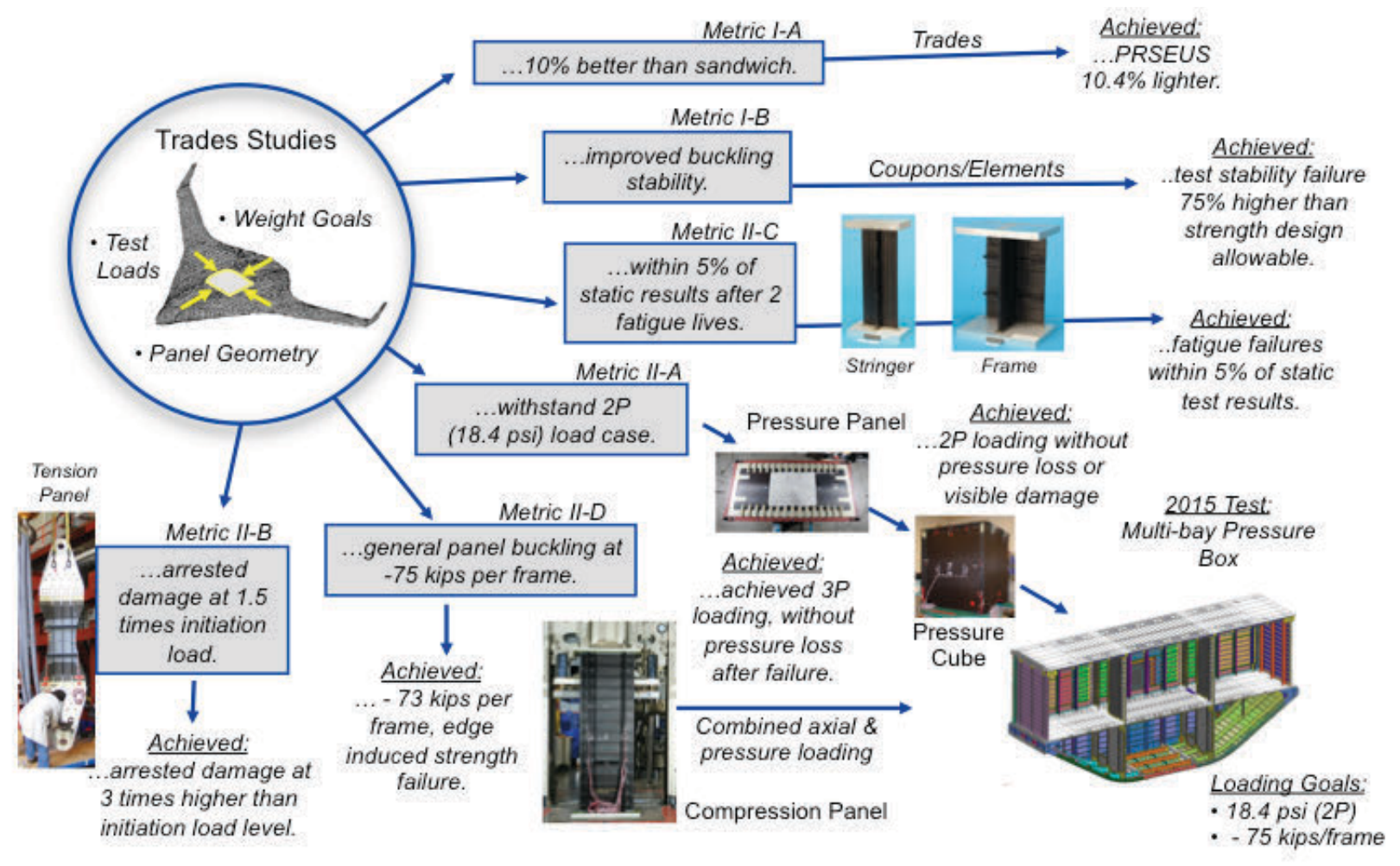

Figure 3. HWB structural development building-block approach. 


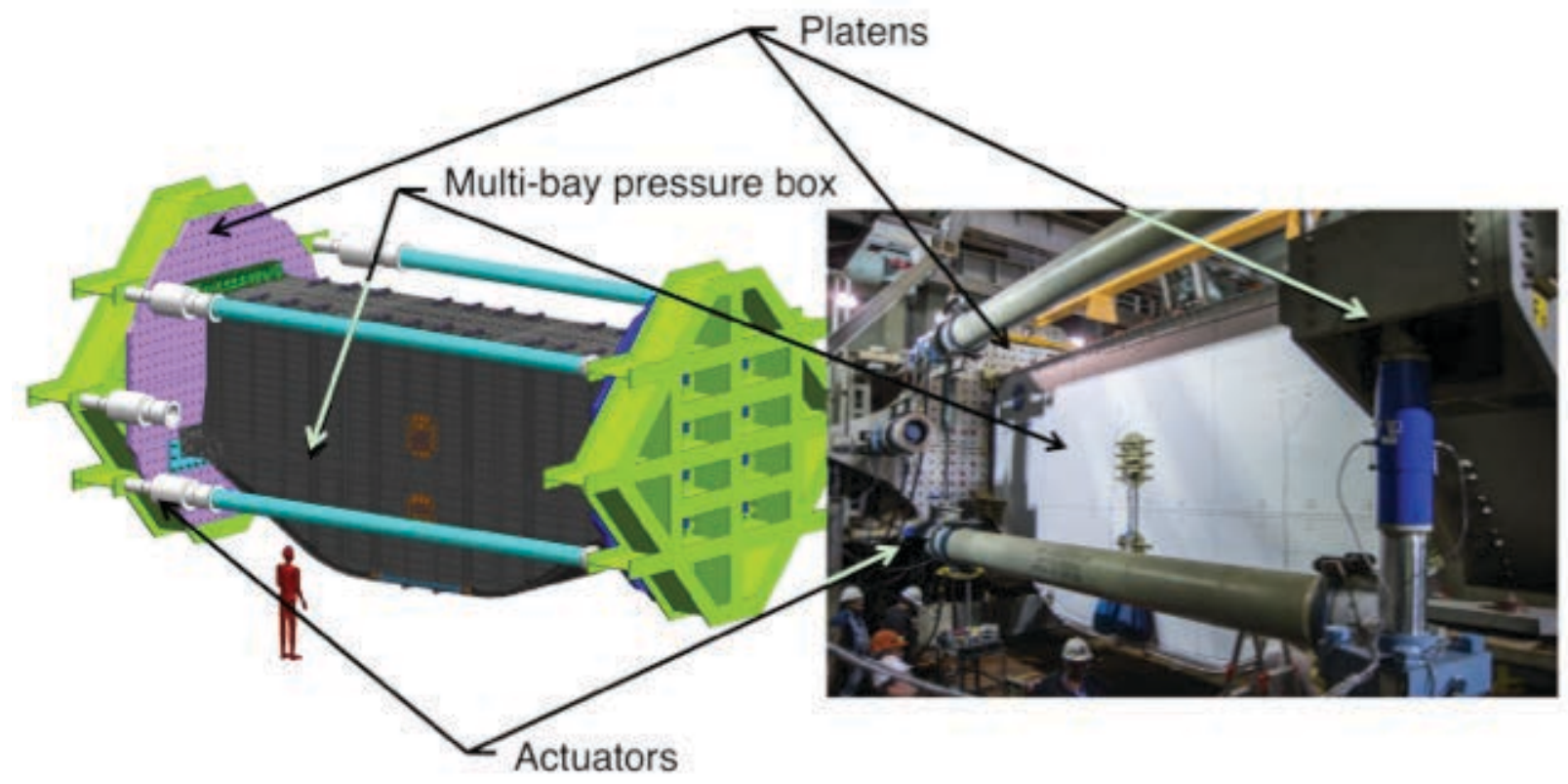

a) Graphical representation

b) Photo in COLTS test chamber

Figure 4. Multi-bay pressure box graphical representation and photograph in the COLTS test chamber.

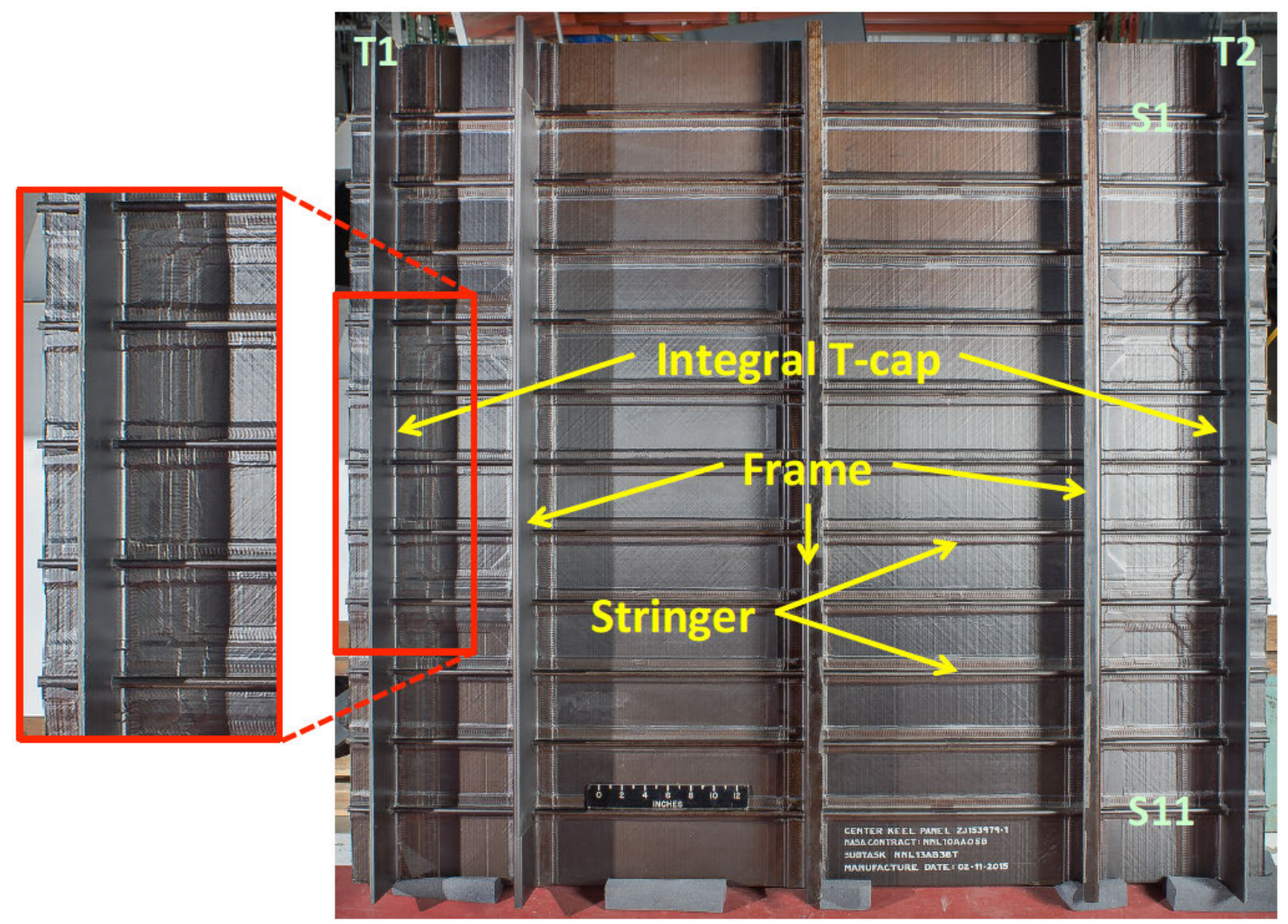

Figure 5. MBB alternate center keel panel with integral T-caps. 


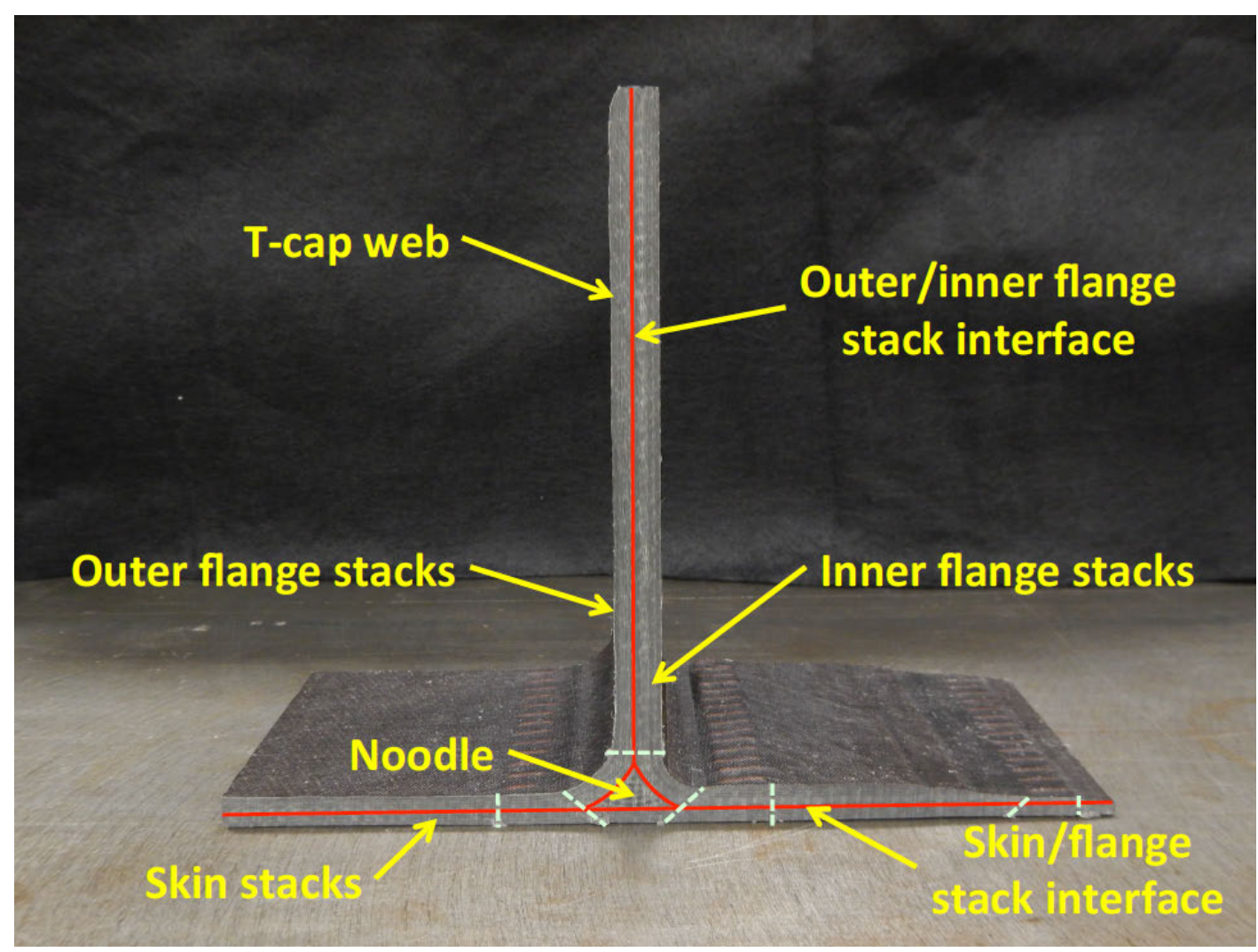

Figure 6. T-cap configuration showing test article cross-section, with light green dashed lines indicating typical manufacturing stitch locations.

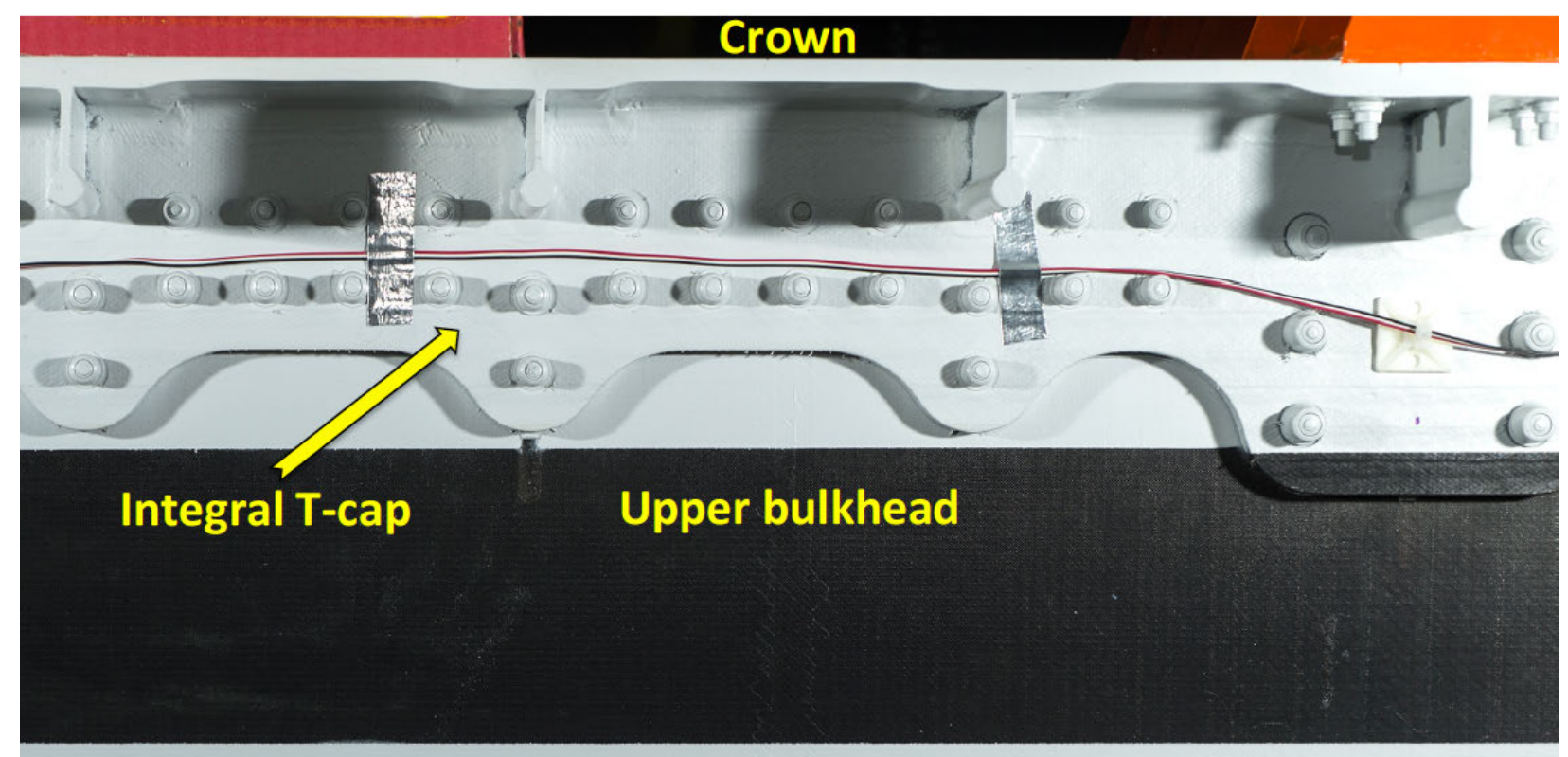

Figure 7. Close-up of crown integral T-cap on MBB.

The objectives of the T-cap testing were as follows:

- Determine the failure loads for various T-cap configurations and designs under tension-only or bendingonly load.

- Identify load at initial failure. 
- Identify maximum sustained load.

- Characterize the failure modes associated with the failure loads identified in conjunction with this objective.

- Provide validation data for future analysis.

\section{Test Article Description}

The T-cap test articles were cut from the alternate keel (Fig. 5) that was manufactured for the MBB as a risk reduction article, as it would supply material in case the MBB needed a repair involving a structural patch. ${ }^{14}$ Since no such repair was required, the alternate keel became the source for a number of component test articles. In addition to the T-cap test articles that are the focus of this report, test articles cut from the alternate keel included stringer compression (including a new wrap), frame compression (including a two new solid frame designs), and stringer push-out (including ones with adhesive between the wrap and rod), all of which are discussed in other reports. ${ }^{15,16}$

The alternate keel included three different T-cap designs for subcomponent testing. The baseline T-cap has only one stitch row at the base of the T-cap web located at the top of the fillet, and is the design that was used in the MBB. The two additional designs added stitching rows to the T-cap web at either 0.5 - or 1.0-inch spacing along the height of the web to determine if there were advantages to additional web stitching. Web stitching patterns for the three designs are shown in Figs. 8a-8c, with the horizontal stitch line locations indicated by the arrows. For each of these web stitch patterns, there are two configurations of test articles, namely one without a stringer and one that has a stringer penetrating the T-cap web through a keyhole. The overall T-cap testing matrix is shown in Table 1. Test articles are of the same general dimensions for both the tension and bending tests, with typical test article crosssection and dimensions shown in Fig. 9, with test articles having a nominal 2.9-inch width. Test article designations are provided in Table 2, with groups of like specimens shown with unshaded or shaded row groupings. In the table, location refers to the T-cap and stringer location from which the test article was cut (see Fig. 5). Due to slight variability in manufacturing, and in variations in cutting the test articles, the test articles vary from the nominal dimensions shown in Fig. 9. Details of these variations are provided in Ref. 17.

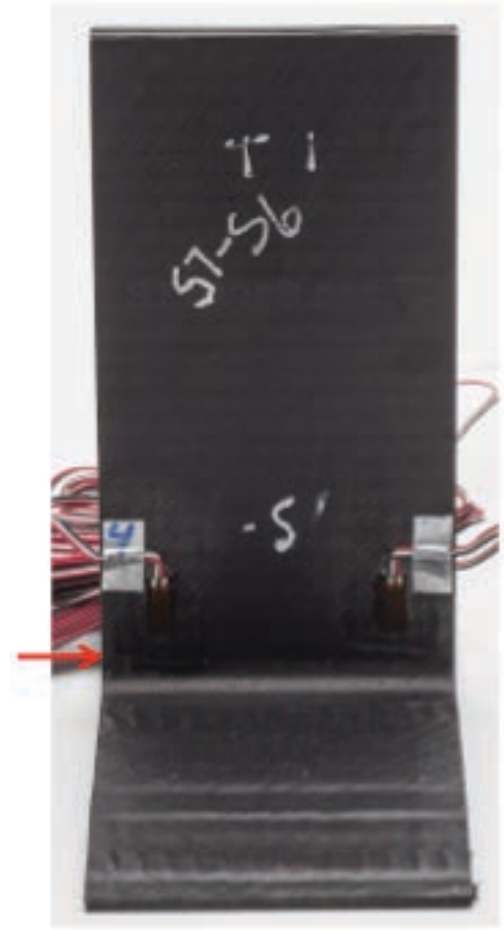

a) Baseline, radius only

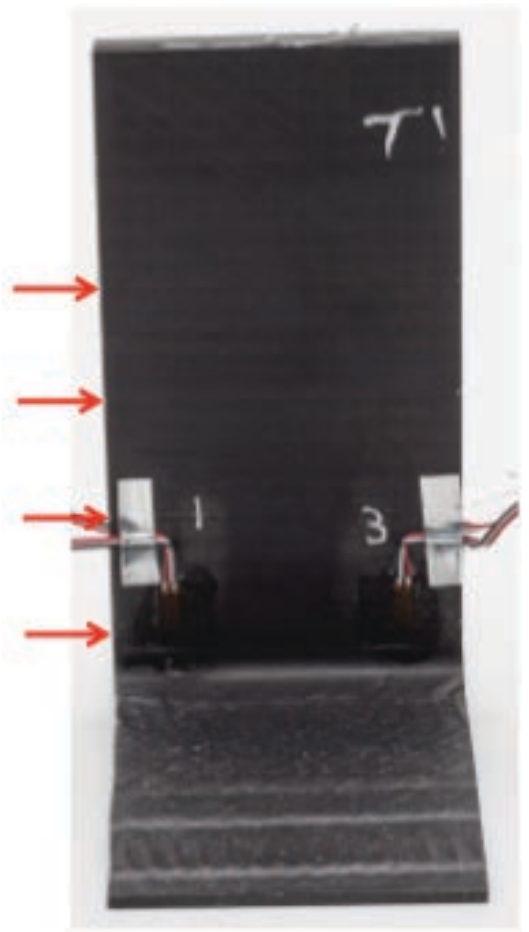

b) 1-inch spacing

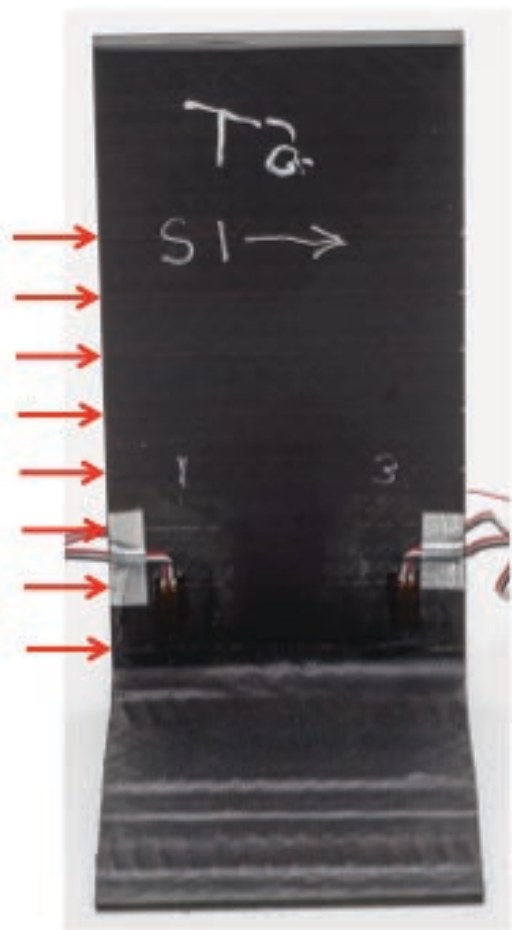

c) $1 / 2$-inch spacing

Figure 8. Views of T-cap web surfaces to show web stitching pattern locations. Arrows indicate locations of web stitch lines. 
Table 1: Summary T-cap testing matrix.

\begin{tabular}{|l|l|l|l|}
\hline Test & Web Stitching & With Stringer & No Stringer \\
\hline \multirow{5}{*}{ Bending } & None (baseline) & 3 & 2 \\
\cline { 2 - 4 } & 0.5 inch spacing & 3 & 3 \\
\cline { 2 - 4 } & 1.0 inch spacing & 3 & 3 \\
\hline \multirow{3}{*}{ Tension } & None (baseline) & 3 & 2 \\
\cline { 2 - 4 } & 0.5 inch spacing & 3 & 3 \\
\cline { 2 - 4 } & 1.0 inch spacing & 3 & 3 \\
\hline
\end{tabular}

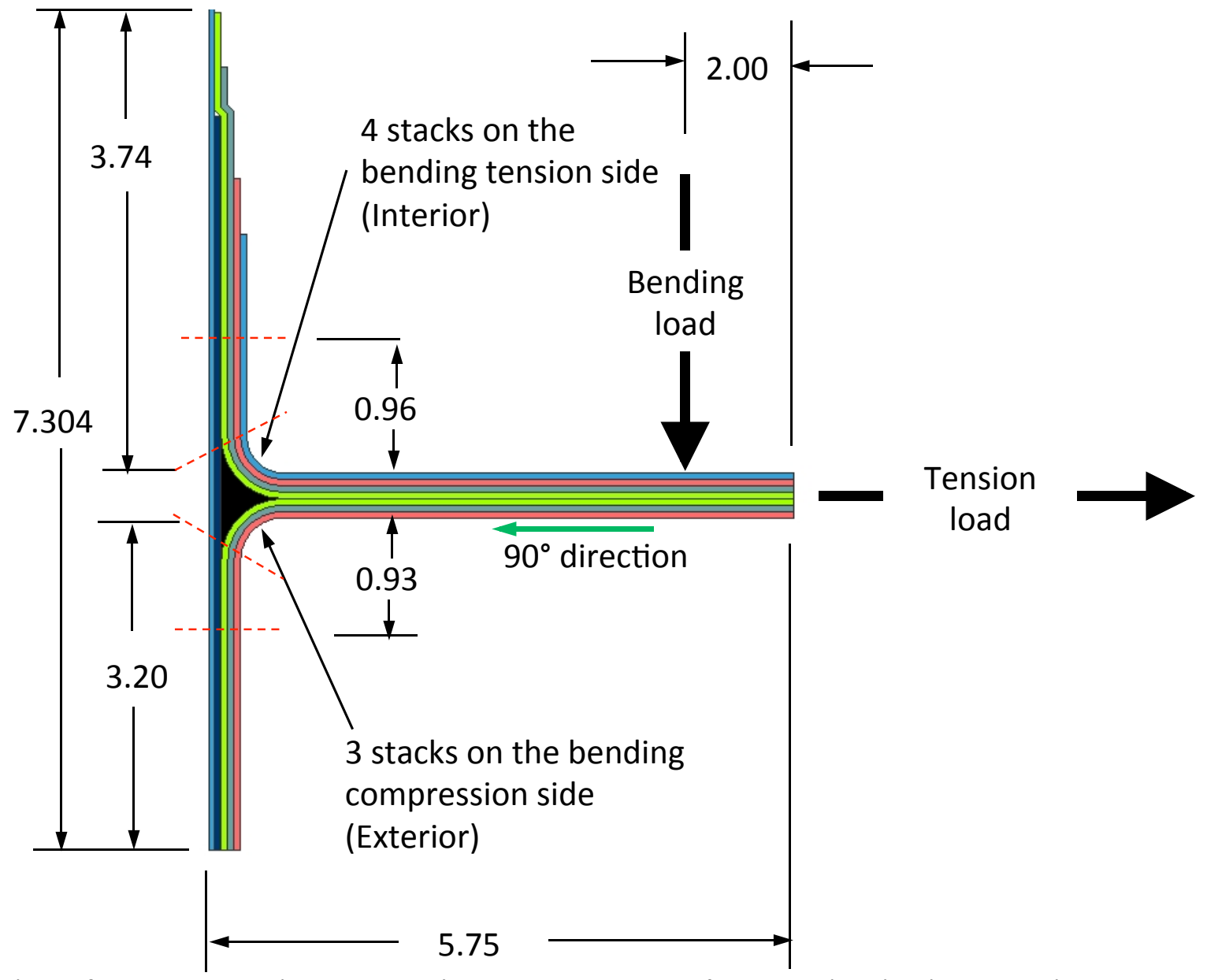

Figure 9. T-cap test article cross-section sketch. The stack 0-degree direction is perpendicular to the crosssection. (Dimensions in inches)

\section{Test Set-up}

The tension and bending T-cap testing was conducted in two load frames located in the Materials Research Laboratory (MRL) at NASA LaRC. The following two sections outline the set-up for the tension and bending tests, respectively.

\section{A. T-cap Tension Test Set-up}

Tension testing of the T-caps was conducted in the 50-kip capacity load frame shown in Fig. 10. The locations of the cameras used for digital image correlation (DIC), a linear variable displacement transducer (LVDT), and other instrumentation features, are shown in the figure and are described in Section V. Instrumentation. The test article 
Table 2: Detailed T-cap testing matrix, T-cap and stringer locations identified in Fig. 5.

\begin{tabular}{|c|c|c|c|c|c|}
\hline $\begin{array}{c}\text { Test Article } \\
\text { ID }\end{array}$ & Test Loading & $\begin{array}{c}\text { Stitching } \\
\text { Spacing (in.) }\end{array}$ & Stringer & $\begin{array}{c}\text { T-cap } \\
\text { Location }\end{array}$ & $\begin{array}{c}\text { Stringer } \\
\text { Location* }\end{array}$ \\
\hline BNS1 & Bending & None & Yes & $\mathrm{T} 1$ & S7 \\
\hline $\mathrm{BNS} 2$ & Bending & None & Yes & $\mathrm{T} 2$ & S5 \\
\hline BNS3 & Bending & None & Yes & $\mathrm{T} 2$ & S6 \\
\hline BNN1 & Bending & None & No & $\mathrm{T} 1$ & S6-S7 \\
\hline $\mathrm{BNN} 2$ & Bending & None & No & $\mathrm{T} 2$ & S6-S7 \\
\hline B5S1 & Bending & 0.5 & Yes & $\mathrm{T} 1$ & S9 \\
\hline $\mathrm{B} 5 \mathrm{~S} 2$ & Bending & 0.5 & Yes & $\mathrm{T} 2$ & $\mathrm{~S} 1$ \\
\hline B5S3 & Bending & 0.5 & Yes & $\mathrm{T} 2$ & $\mathrm{~S} 2$ \\
\hline $\mathrm{B} 5 \mathrm{~N} 1$ & Bending & 0.5 & No & $\mathrm{T} 1$ & S11-S12 \\
\hline $\mathrm{B} 5 \mathrm{~N} 2$ & Bending & 0.5 & $\mathrm{No}$ & $\mathrm{T} 2$ & $\mathrm{~S} 1-$ \\
\hline $\mathrm{B} 5 \mathrm{~N} 3$ & Bending & 0.5 & No & $\mathrm{T} 2$ & S2-S3 \\
\hline B1S1 & Bending & 1 & Yes & $\mathrm{T} 1$ & S3 \\
\hline B1S2 & Bending & 1 & Yes & $\mathrm{T} 2$ & $\mathrm{~S} 10$ \\
\hline B1S3 & Bending & 1 & Yes & $\mathrm{T} 2$ & $\mathrm{~S} 11$ \\
\hline B1N1 & Bending & 1 & No & $\mathrm{T} 1$ & S1- \\
\hline B1N2 & Bending & 1 & No & $\mathrm{T} 2$ & S9-S10 \\
\hline B1N3 & Bending & 1 & No & $\mathrm{T} 2$ & S10-S11 \\
\hline TNS1 & Tension & None & Yes & $\mathrm{T} 1$ & S5 \\
\hline TNS2 & Tension & None & Yes & $\mathrm{T} 1$ & S6 \\
\hline TNS3 & Tension & None & Yes & $\mathrm{T} 2$ & S7 \\
\hline TNN1 & Tension & None & No & $\mathrm{T} 1$ & S5-S6 \\
\hline TNN2 & Tension & None & No & $\mathrm{T} 2$ & S5-S6 \\
\hline T5S1 & Tension & 0.5 & Yes & $\mathrm{T} 2$ & S3 \\
\hline $\mathrm{T} 5 \mathrm{~S} 2$ & Tension & 0.5 & Yes & $\mathrm{T} 1$ & $\mathrm{~S} 10$ \\
\hline T5S3 & Tension & 0.5 & Yes & $\mathrm{T} 1$ & S11 \\
\hline T5N1 & Tension & 0.5 & No & $\mathrm{T} 1$ & S11+ \\
\hline T5N2 & Tension & 0.5 & No & $\mathrm{T} 1$ & S9-S10 \\
\hline T5N3 & Tension & 0.5 & No & $\mathrm{T} 2$ & $\mathrm{~S} 1-\mathrm{S} 2$ \\
\hline T1S1 & Tension & 1 & Yes & $\mathrm{T} 1$ & $\mathrm{~S} 1$ \\
\hline T1S2 & Tension & 1 & Yes & $\mathrm{T} 1$ & $\mathrm{~S} 2$ \\
\hline T1S3 & Tension & 1 & Yes & $\mathrm{T} 2$ & S9 \\
\hline T1N1 & Tension & 1 & No & $\mathrm{T} 1$ & $\mathrm{~S} 1-\mathrm{S} 2$ \\
\hline T1N2 & Tension & 1 & No & $\mathrm{T} 1$ & S2-S3 \\
\hline T1N3 & Tension & 1 & No & $\mathrm{T} 2$ & S11+ \\
\hline
\end{tabular}

* S\#-S\#\# indicates located between stringers \# and \#\#, and S\#+ or S\#- indicates located between stringer \# and the edge of the panel.

was bolted to a base plate fitting that was gripped by the hydraulic grip mounted to the load cell at the base of the load frame, as identified in Fig. 11. The web of the test article is gripped by an upper hydraulic grip that is kept from sliding on the test article by the presence of a diamond knurl pattern on the surface of the grip wedges. Grip hydraulic pressure was set between 1000 and 1200 psi. The upper grip was located such that two inches of the T-cap web was within the grip wedges, which exposed a height of the T-cap web of 3.75 inches as measured from the outer mold line. Both the inner and outer skin/flange regions are bolted to the base plate, each having two bolts and a clamp plate with a slot to accomodate the stringer web. Also seen in Fig. 11 are shims that are inserted at the inner skin/flange location to account for the stack drops, with shimming required for all test articles at this location. For the test articles having a stiffener, there were also shims used on the outer skin portion. Details of the base plate fitting and clamp plates are provided in Appendix A of Ref. 17, which includes the drill template that was used for drilling tension and bending test articles to match the fixture components. 


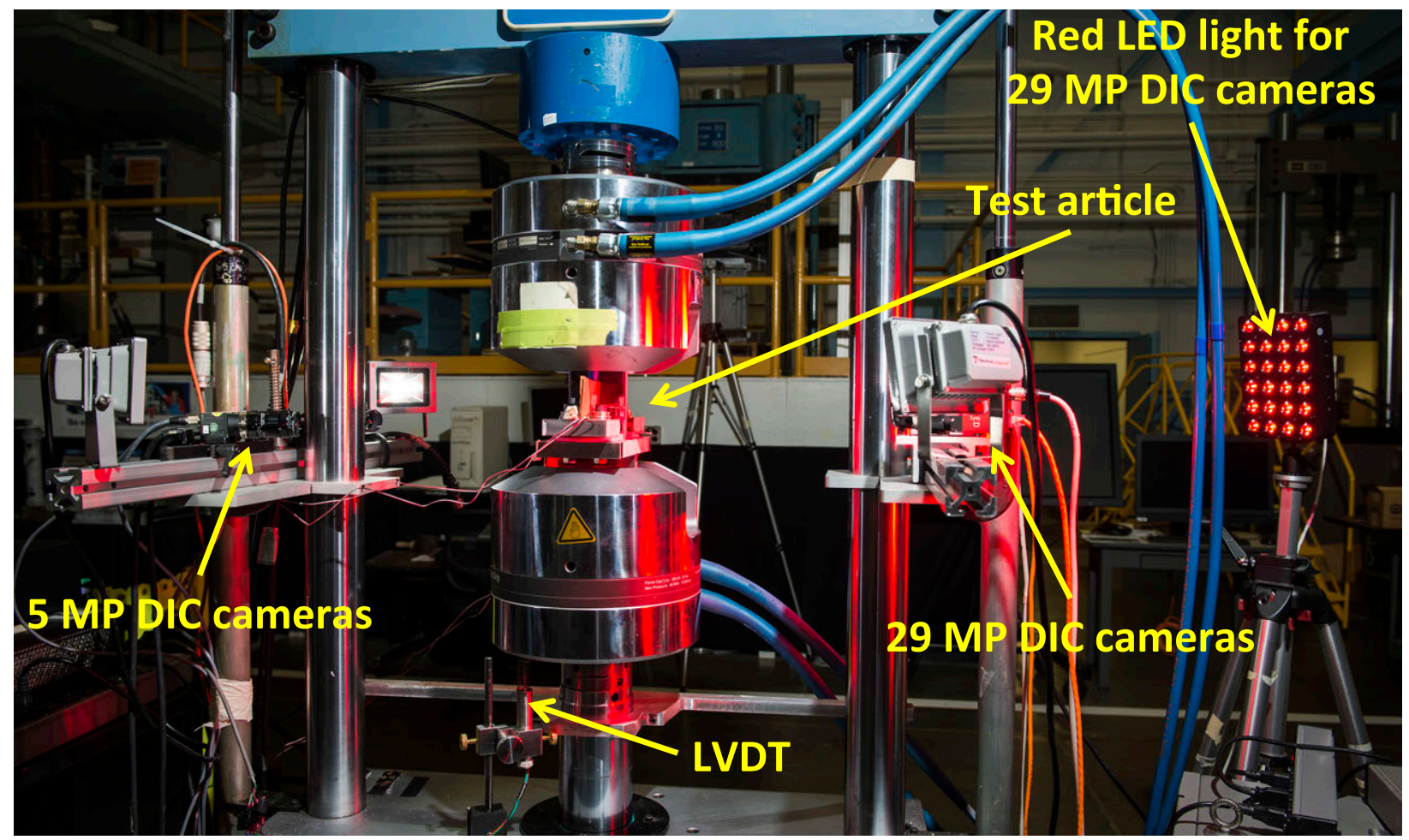

Figure 10. T-cap tension test load frame with 50-kip load capacity.

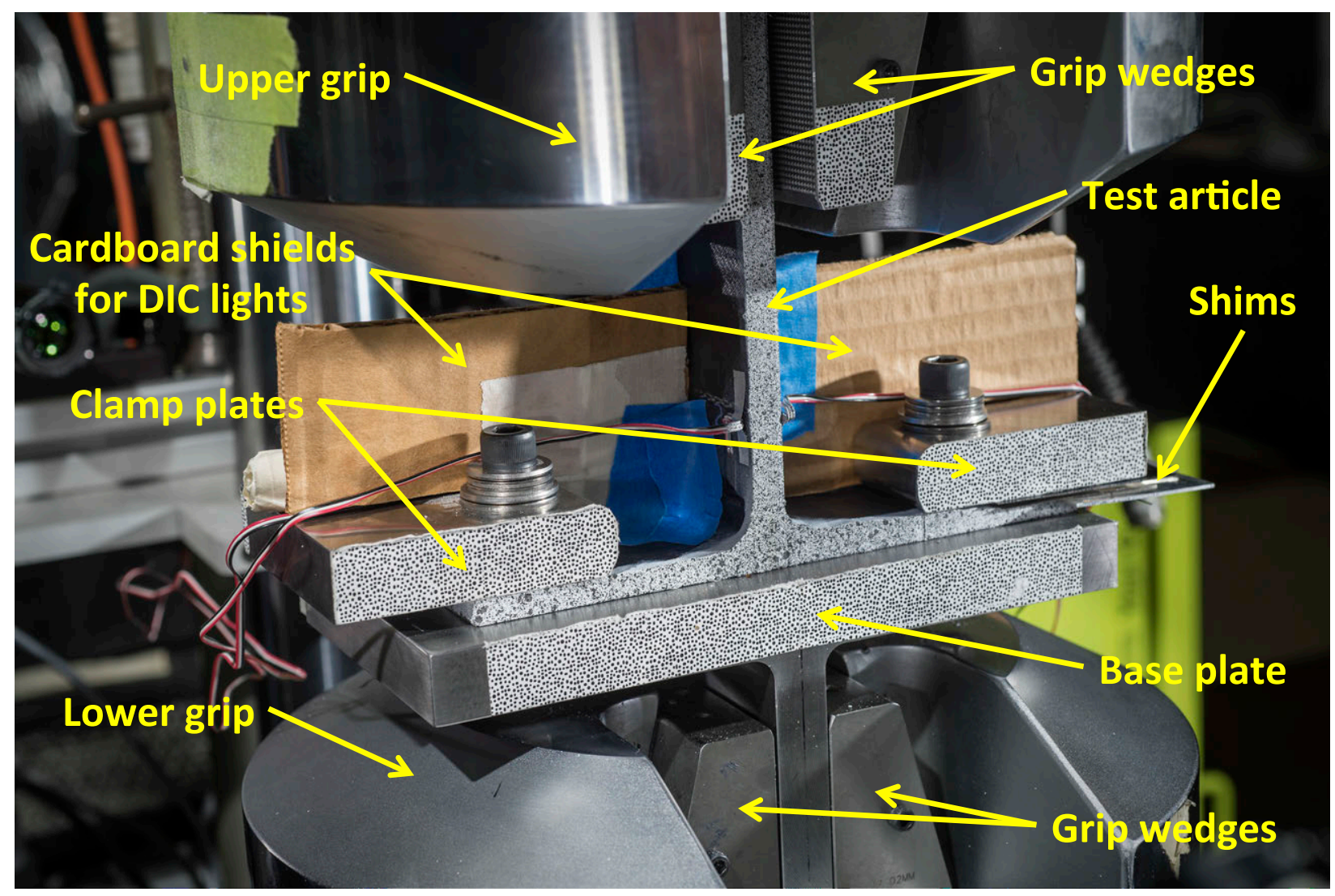

Figure 11. Close-up of stringerless T-cap test article mounted in tension load frame. (View from 29MP DIC system side) 


\section{B. T-cap Bending Test Set-up}

Bending testing of the T-caps was conducted in a 2.5-kip capacity load frame as shown in Fig. 12. The test article was bolted to an assembly via slots located at the base of the load frame. The clamp plates from the tension tests were used for the bending tests. Similarly, the test article was shimmed on the inner skin/flange region for all test articles, and on the outer skin/flange region for the test articles having stringers. A close-up of a test article mounted in the load frame is shown in Fig. 13. The pusher that applies the line load to induce bending was attached using a threaded rod, connecting it to the load cell that is mounted on the upper portion of the load frame. As shown in Fig. 9, the bending line load was applied at a distance of 3.75 inches from the skin outer mold line. Details of the bending test fixture components are provided in Appendix B of Ref. 17.

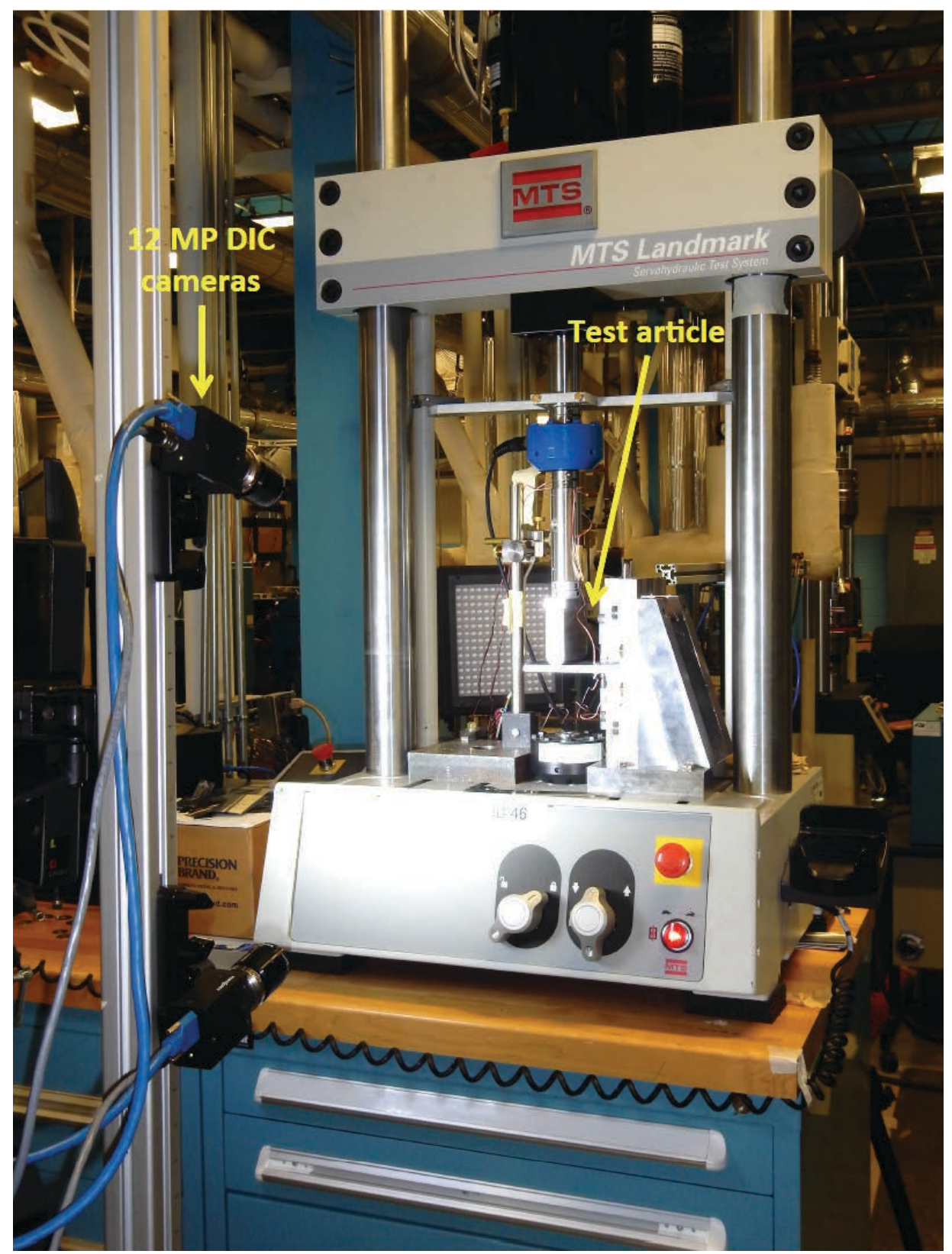

Figure 12. T-cap bending test load frame with 2.5-kip load capacity. (View from front) 


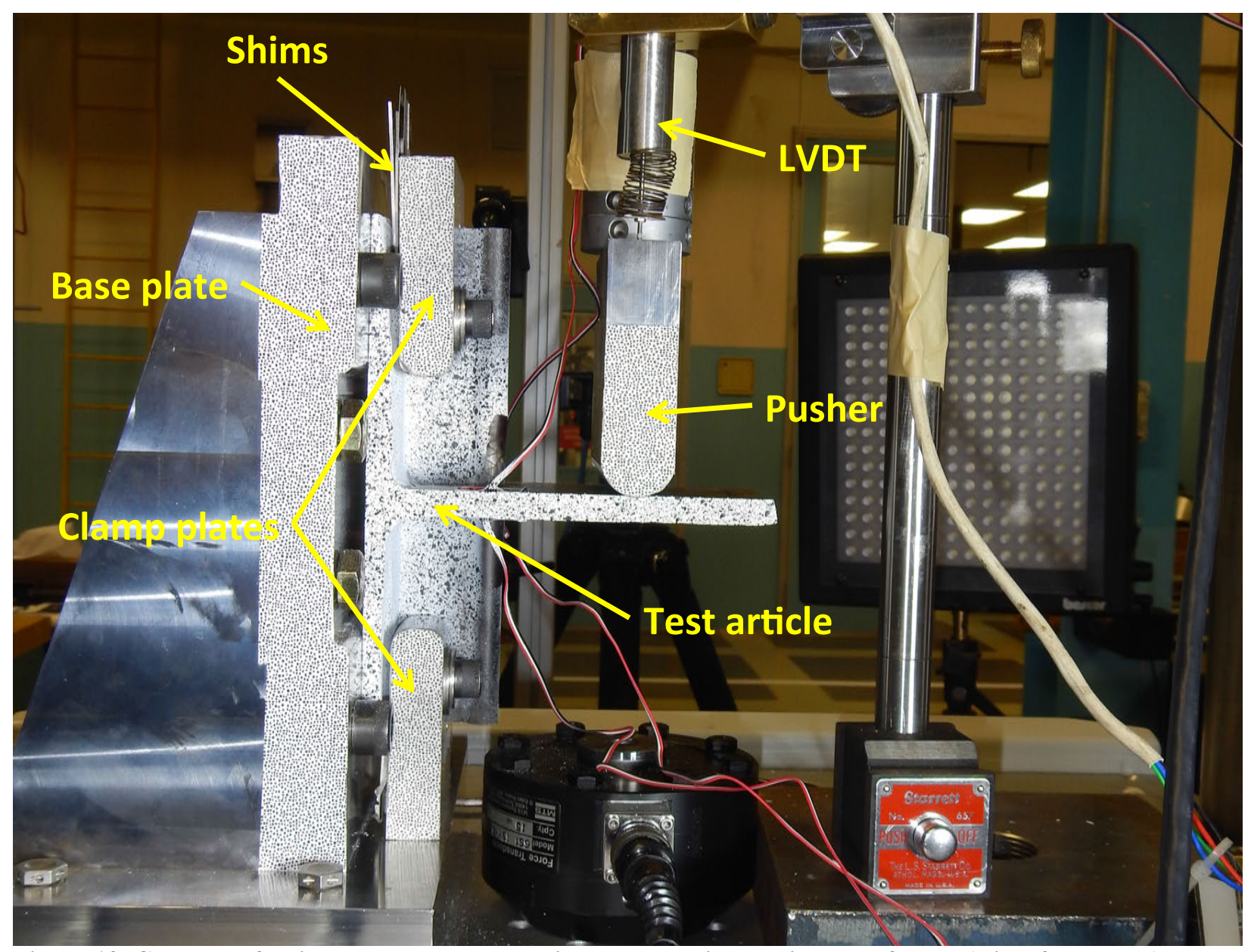

Figure 13. Close-up of stringerless T-cap test article mounted in bending load frame. (View from back)

\section{Test Conditions and Summary}

The tests were performed at ambient room temperature in the high bay of the MRL. The load frames applied load under displacement control, and each test article was loaded until failure occurred as determined by the test engineer. Initial failure is defined as the initiation of delaminations, while total failure was defined as having reached the maximum load attainable for the test article. Test article response was measured and recorded using standard instrumentation and digital image correlation techniques.

Each of the 34 test articles identified in Table 2 was loaded in a single load sequence. Uniform displacement was monotonically applied, with the resulting load being measured by the load cell, until failure occurred. The anticipated failure mechanism was expected to be delamination and separation in the radius region of the T-cap web/flange interface or below the web within the noodle region adjacent to the skin stack. Stitches were expected to arrest the delaminations until stitch failure allowed the failures to grow. Details of the failure growth are discussed for each test article in Section VI. Test Data and Discussion.

The stroke rates used for the testing depended on the presence of a stringer and on load type. Table 3 shows the loading rates that were used for each test article. The stroke rate for the tension test articles was kept constant throughout each test. However, the stroke rate for the bending tests was increased after several delamination failures were observed, and after the behavior became reasonably stable, in order to shorten the length of the tests. Tension tests typically took about 8-10 minutes for the stringerless test articles, and 18-20 minutes for the stringer test articles. Bending tests typically took about 18-20 minutes for the stringerless test articles, and 12-17 minutes for the stringer test articles.

For the tension tests, the test articles were drilled to match the base plate using a drill template. The test articles were positioned so that the web of the integral T-cap was co-planar with and centered above the tang of the base plate. However, due to tolerance allowances, it was not possible to guarantee that this alignment was attained. 
Table 3: Stroke rates for T-cap testing.

\begin{tabular}{|c|c|c|c|c|c|}
\hline \multicolumn{2}{|c|}{ Tension Test Articles } & \multicolumn{4}{|c|}{ Bending Test Articles } \\
\hline \multirow[b]{2}{*}{ ID } & \multirow{2}{*}{$\begin{array}{c}\text { Initial } \\
\text { Rate (in/min) }\end{array}$} & \multirow[b]{2}{*}{ ID } & \multirow{2}{*}{$\begin{array}{c}\text { Initial } \\
\text { Rate (in/min) }\end{array}$} & \multicolumn{2}{|c|}{ Accelerated } \\
\hline & & & & Rate (in/min) & (a) stroke (in) \\
\hline TNS1 & 0.01 & BNS1 & 0.04 & $\mathrm{~N} / \mathrm{A}$ & N/A \\
\hline TNS2 & 0.01 & BNS2 & 0.04 & 0.08 & 0.4 \\
\hline TNS3 & 0.01 & BNS3 & 0.05 & 0.1 & 0.4 \\
\hline TNN1 & 0.02 & BNN1 & 0.025 & $\mathrm{~N} / \mathrm{A}$ & N/A \\
\hline TNN2 & 0.02 & BNN2 & 0.05 & 0.1 & 0.5 \\
\hline T5S1 & 0.01 & B5S1 & 0.04 & 0.08 & 0.4 \\
\hline $\mathrm{T} 5 \mathrm{~S} 2$ & 0.01 & B5S2 & 0.05 & 0.1 & 0.4 \\
\hline T5S3 & 0.01 & B5S3 & 0.05 & 0.1 & 0.4 \\
\hline T5N1 & 0.02 & B5N1 & 0.05 & 0.1 & 0.5 \\
\hline T5N2 & 0.02 & B5N2 & 0.05 & 0.1 & 0.52 \\
\hline T5N3 & 0.02 & B5N3 & 0.05 & 0.1 & 0.45 \\
\hline T1S1 & 0.01 & $\mathrm{~B} 1 \mathrm{~S} 1$ & 0.04 & 0.08 & 0.425 \\
\hline T1S2 & 0.01 & B1S2 & 0.05 & 0.1 & 0.42 \\
\hline T1S3 & 0.01 & B1S3 & 0.05 & 0.1 & 0.45 \\
\hline T1N1 & 0.02 & B1N1 & 0.05 & 0.1 & 0.4 \\
\hline $\mathrm{T} 1 \mathrm{~N} 2$ & 0.02 & B1N2 & 0.05 & 0.1 & 0.5 \\
\hline T1N3 & 0.02 & B1N3 & 0.05 & 0.1 & 0.5 \\
\hline
\end{tabular}

Therefore, strains were measured during the gripping of the T-cap web by the upper grip in order to characterize the induced bending and twist that resulted from any misalignment. Strains were measured during loading from this initial strain state such that the strains measured during the test included both the initial prestrain due to misalignment and the applied load. For the bending tests, the test articles were drilled to match the base plate so that the T-cap web plane was perpendicular to the plane of the pusher, and the pusher attains line contact simultaneously along the width of the web. However, due to tolerance allowances, this was not always the case and any twist that may have been introduced due to misalignment was immediately apparent upon the introduction of the load, and the strains through the test again were a measure of the total strain that included strains introduced by misalignment and the applied load.

\section{Instrumentation}

Each test article had responses measured and recorded using standard instrumentation and digital image correlation techniques. Displacements of the actuated components were recorded using an LVDT, and load frame stroke was also recorded. Strain gages were used to monitor load symmetry. DIC was used to monitor the response, and the displacement and strains of both of the test article cross-section surfaces and adjacent test fixtures. Additional details of the instrumentation is provided in the following sections.

\section{A. Conventional Instrumentation}

The strain gage pattern is shown in Fig. 14, and consists of two back-to-back pairs of strain gages. Gages 1 and 3 are on the same surface of the test article, and gages 2 and 4 are back-to-back to gages 1 and 3 , respectively. Typically, gages 1 and 3 were located on the interior surface of the T-cap web, with gages 2 and 4 being on the exterior surface of the T-cap web (see Fig. 9). However, several of the test articles had gages 1 and 3 installed on the exterior surface of the T-cap web, details of which are in Ref. 17. Strain gages were used, and had 10-ft. lead wires to reach the data acquisition system. The gages were used to monitor gross response of the web during loading, as mentioned previously, to monitor if bending was being applied during clamping of the test article web by the grips during the tension tests, and to monitor if twisting was being applied to the web during initial contact of the pusher during the bending tests. 


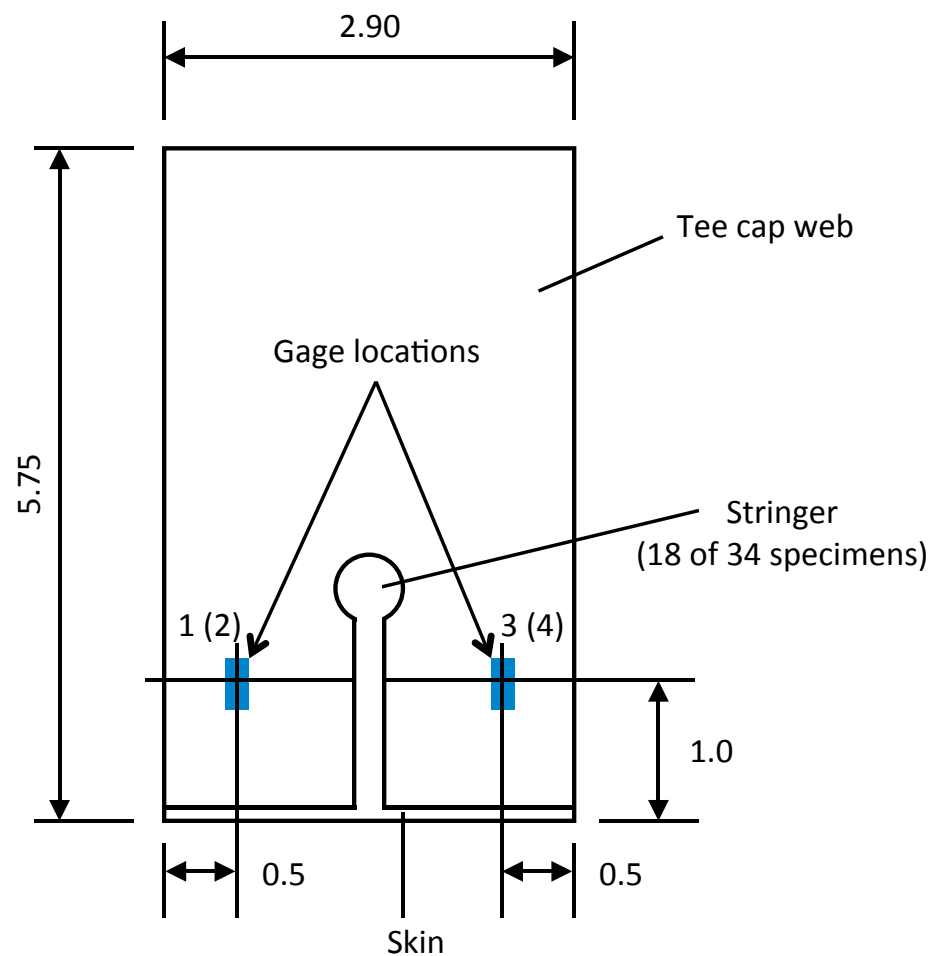

Figure 14. T-cap strain gage pattern for all test articles.

An LVDT was used to record the displacements of the actuated grip and the pusher for the tension and bending tests, respectively. Locations of the LVDT can be seen in Figs. 10 and 12 for the tension and bending tests, respectively. Load frame stroke was also recorded during loading for direct comparison to the LVDT. During the tests, response was monitored by plots of load versus stroke, load versus LVDT displacement, and strains versus stroke. Additionally, since the process of gripping of the test article web for the tension tests could induce strains, the strains were monitored during clamping to determine the strain state prior to applying the tension load.

\section{B. DIC}

DIC was used to monitor the response of the T-cap cross-sections and the adjacent fixture components. The DIC set-up for the tension and bending test articles was different. For the tension tests, different camera arrangements were used to view the opposite sides of the test article. One used a set of Allied Vision Technologies Prosilica GT6600 (29 MP) cameras ${ }^{18}$ with a single field of view that encompassed the entire T-cap cross-section and the horizontal part of the base plate for one side of the test article. The 29 MP cameras viewed the test article with the interior portion of the skin on the right side of the image. The other side of the test article was viewed using two sets of Point Grey Flea3 FL3-GE-50S5M-C (5 MP) cameras $^{19}$, one for a global view of the T-cap cross-section and the horizontal part of the base plate, and one that was localized on the noodle region at the T-cap web/flange interface. The global and local 5 MP cameras viewed the test article with the interior portion of the skin on the left side of the image. Fig. 15 shows the approximate area of the test article that was covered by the local DIC, which was a field of view approximately 1.5 inches high and 2.0 inches wide. For the bending tests, the same arrangement was used for both sides of the test article. The camera set-up used a set of Point Grey Grasshopper3 GS3-U3-120S6M-C (12 MP) cameras ${ }^{19}$ with a single field of view that encompassed the entire T-cap cross-section and the adjacent fixture. Part of the grip wedges were included in the field of view for the tension test global systems, and the pusher was included in the field of view for the bending systems.

White light sources were used for all DIC, with the exception of the area covered by the tension testing GT6600 cameras for which red LED light sources were used (identified in Fig. 10). In the case of the tension tests, it was necessary to mask regions not filled by the test article to avoid interference from opposing lighting sources. This was accomplished using cardboard as seen in Fig. 11. Additionally, a piece of folded tape was put between the base plate and the test specimen to block light when a separation occurred during loading. DIC was performed using the 


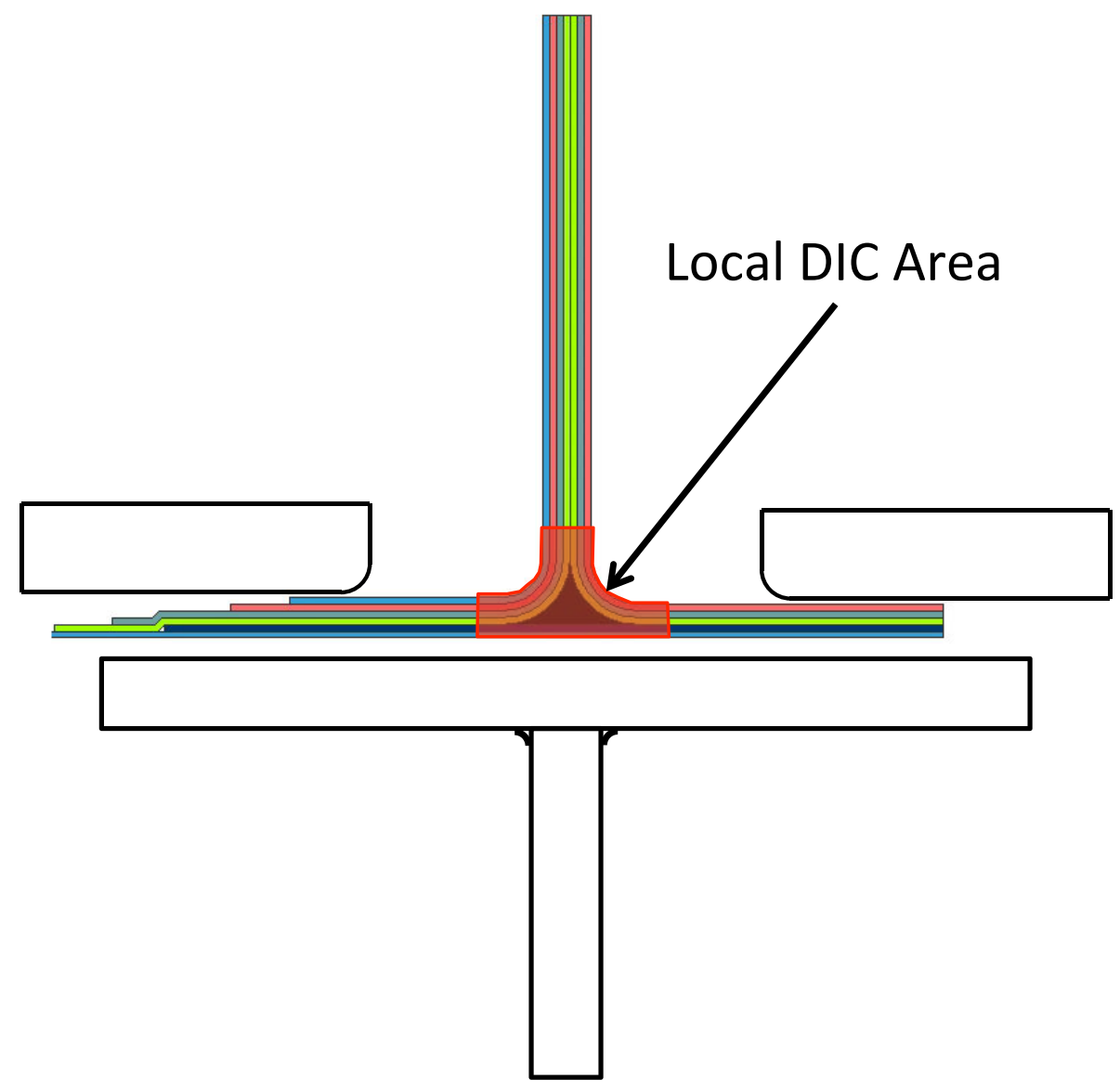

Figure 15. Tension test DIC region coverage area surfaces and local DIC area.

Correlated Solutions VIC3D software. ${ }^{20}$ Real-time data were displayed during the test to monitor strains and displacements. Load was recorded by each DIC system and correlated with the image numbers.

\section{Test Data and Discussion}

Test data for the 34 test articles are presented in Appendix C of Ref. 17. Data presented included xy-plots of load versus stroke and load versus strain, contour plots of strains at various loads for selected test articles (one of each test article type), and images of the failures that occurred for the selected test articles for which strain contours were provided. This section summarizes and discusses the test data presented in the reference.

There are several pieces of information that are needed to satisfy the previously stated objective of determining the failure loads for the various T-cap configurations under only tension or bending load. First was to identify the initial failure load and the associated mode, and second was to identify the maximum load and associated failure mode. Between these failure loads, it is desired to identify and characterize the progression of the damage growth. Loads have been primarily obtained by looking at the strain versus load and load versus stroke plots for each test article. Figure 16 shows the strain versus load plot for the TNS1 test article during the initial loading up to 4,000 lb. Non-zero strains at zero load represent bending strains that were introduced during the clamping process by the test frame grip, a condition that was seen by most of the test articles. On the figure there is a discontinuity in the strain gage plot for gage \#3 at just over 2,000 lbs. However, this response is localized as there is no corresponding change in plots for the remaining strain gages or the DIC data, and it is thus considered as a possible edge effect. The first load at which all four gages show a change in response, even though the movement was slight, was at 2,593 lbs. This value is chosen as the initial failure load since it resulted in a delamination that spanned the entire width of the test article, as was indicated by the DIC data. As seen in Fig. 17 for the TNS1 test article, there is no appreciable load drop associated with this event, but it is clearly indicated in the strain gage data. The maximum load is obtained 
from the load versus stroke plot as indicated in Fig. 17, and is 7,287 lbs. Additionally, there were times that the DIC strain contour plots were used to identify the initial delamination failure as the DIC data indicated the presence of failures that did not result in observable changes in any of the conventional data plots.

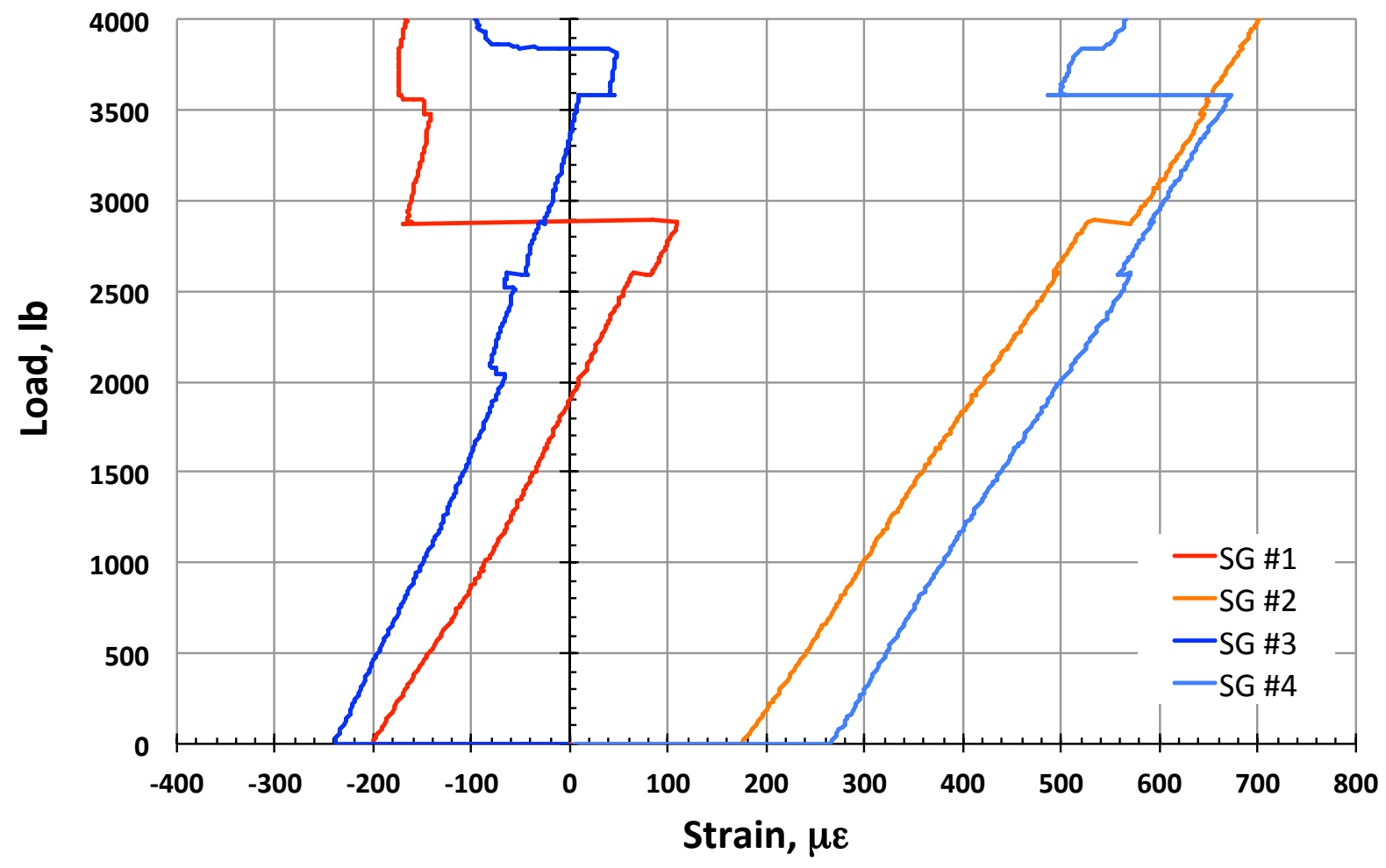

Figure 16. TNS1 Load versus strain, initial loading up to $4000 \mathrm{lb}$.

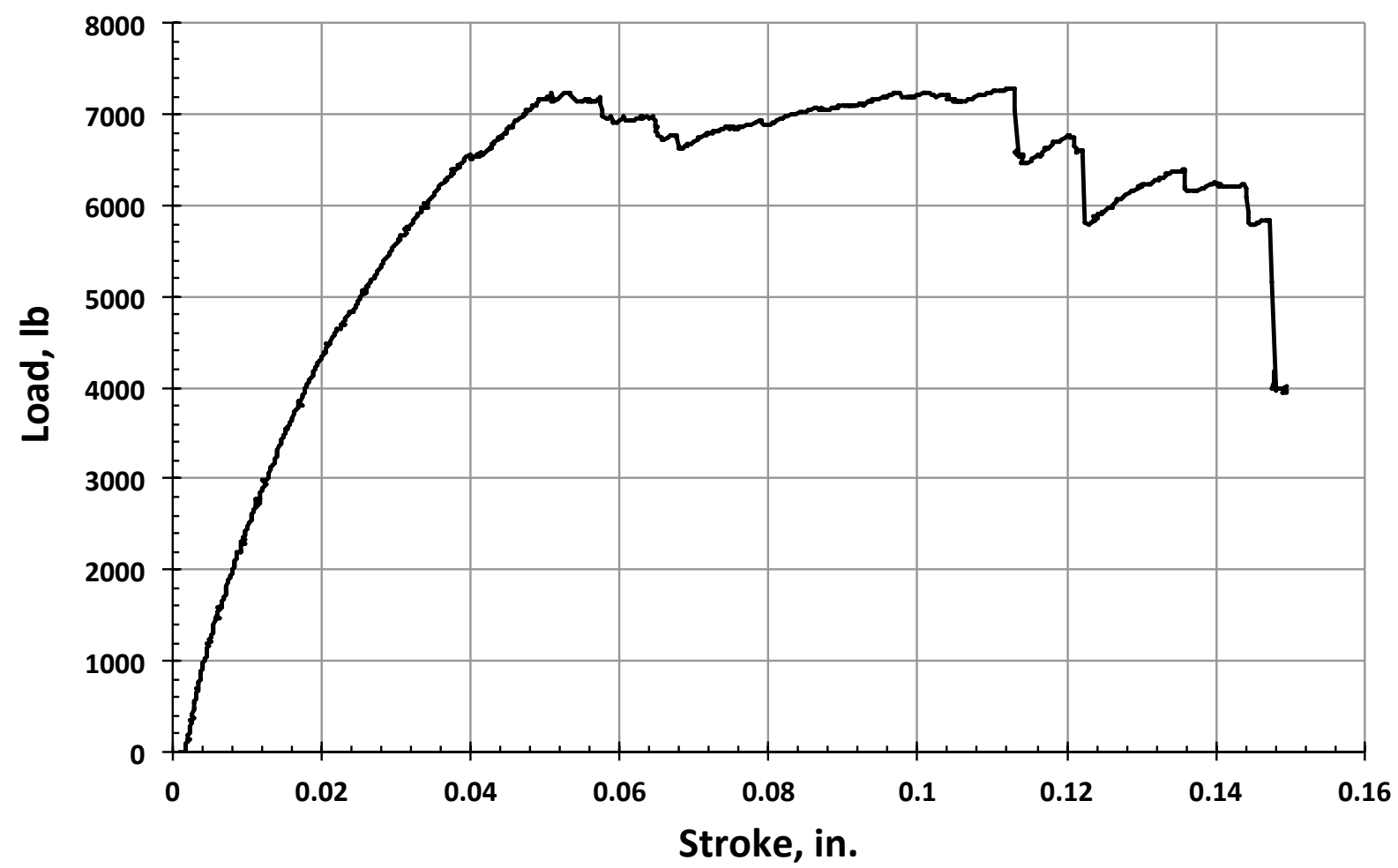

Figure 17. TNS1 Load versus stroke throughout entire test cycle.

15

American Institute of Aeronautics and Astronautics 
Initial failure and maximum achieved running loads/moments were compiled and are summarized in Tables 4 and 5 for the tension-only and bending-only tests, respectively. These results are graphed for ease of comparison in Figs. 18 and 19 for the tension-only and bending-only T-cap tests, respectively. In these figures, the test articles are identified and grouped according to configuration and design. In these plots, the initial failure load is shown by the darker solid portion of the bar, and the partially transparent lighter extension of the bar identifies the maximum value that was attained. Also included in the plots is the average value for each of the test article configurations within each design, and is located on the right side of each grouping in a lighter color variation from the test articles.

The data from Figs. 18 and 19 are tabulated in Table 6 in the form of normalized average initial failure and average maximum loads. The normalizing load is the corresponding average load for the baseline configuration without web stitching, with or without the stiffener present. The data provide some interesting observations concerning the effects of the additional stitching in the new integral T-cap designs, as well as with the presence of the stiffener. Notice that the initial failure load for tension-only is adversely affected by the additional T-cap web stitching. The average initial failure load decreases by $7.7 \%$ and $10.3 \%$ for the designs with 1 -inch and 0.5 -inch stitch spacing in the T-cap web, respectively, for test articles without a stiffener. Failures initially occur as delamination in the vicinity of the noodle region at the base of the T-cap web. As the displacement was applied to the test article, the load continued to increase and then drop as additional delamination regions were created. Delaminations grew to the stitching in the web and/or the flange regions and were arrested by the stitching. There were load drops associated with failures of the stitches, which typically resulted in some of the largest load drops. For the test articles with a stiffener present, the initial failure load decreases by $0.1 \%$ and $0.8 \%$ for the designs with 1-inch and 0.5-inch stitch spacing in the T-cap web, respectively, which is not a significant deviation. However, as seen in Table 4, the initial failure loads for the test articles with stiffeners were significantly higher than those without a stiffener, about $16 \%$ higher than the baseline test article wthout the stiffener. Initial failures for the stiffener test articles occur as delaminations in the vicinity of the noodle at the intersection of the T-cap web and flanges, as was seen in the stiffenerless test articles. However, early in the loading there were small audible pops that were likely associated with the keyhole/stiffener junction as no evidence of delaminations was observed. As loading continued, in addition to the delaminations that continued to form, failures were also observed in the web of the stiffener indicating that load was being passed through the stiffener to the skin/flange region away from the T-cap web.

Table 4: Tension T-cap test initial failure and maximum attained running loads, $\mathrm{Nx}$ (lb/in).

\begin{tabular}{|c|c|c|c|c|}
\hline Test Article & Initial Failure & Maximum & Initial Failure Ave. & Maximum Ave. \\
\hline TNN1 & 787 & 914 & \multirow[b]{2}{*}{784} & \multirow[b]{2}{*}{914} \\
\hline TNN2 & 781 & 914 & & \\
\hline T1N1 & 743 & 858 & \multirow[b]{3}{*}{723} & \multirow[b]{3}{*}{924} \\
\hline T1N2 & 684 & 862 & & \\
\hline T1N3 & 743 & 1,052 & & \\
\hline $\mathrm{T} 5 \mathrm{~N} 1$ & 688 & 1,118 & \multirow[b]{3}{*}{703} & \multirow[b]{3}{*}{1,009} \\
\hline T5N2 & 711 & 943 & & \\
\hline T5N3 & 710 & 964 & & \\
\hline TNS1 & 889 & 2,494 & \multirow[b]{3}{*}{911} & \multirow[b]{3}{*}{2,610} \\
\hline TNS2 & 872 & 2,415 & & \\
\hline TNS3 & 971 & 2,922 & & \\
\hline T1S1 & 1,214 & 2,558 & \multirow[b]{3}{*}{910} & \multirow[b]{3}{*}{2,717} \\
\hline T1S2 & 748 & 2,602 & & \\
\hline T1S3 & 768 & 2,992 & & \\
\hline T5S1 & 888 & 2,535 & \multirow[b]{3}{*}{903} & \multirow[b]{3}{*}{2,935} \\
\hline T5S2 & 753 & 3,014 & & \\
\hline T5S3 & 1,069 & 3,256 & & \\
\hline
\end{tabular}


Table 5: Bending T-cap test initial failure and maximum attained running moments, Mx (in-lb/in).

\begin{tabular}{|c|c|c|c|c|}
\hline Test Article & Initial Failure & Maximum & Initial Failure Ave. & Maximum Ave. \\
\hline BNN1 & 479 & 670 & \multirow[b]{2}{*}{447} & \multirow[b]{2}{*}{753} \\
\hline BNN2 & 414 & 837 & & \\
\hline B1N1 & 514 & 909 & \multirow[b]{3}{*}{446} & \multirow[b]{3}{*}{829} \\
\hline $\mathrm{B} 1 \mathrm{~N} 2$ & 447 & 797 & & \\
\hline $\mathrm{B} 1 \mathrm{~N} 3$ & 377 & 781 & & \\
\hline $\mathrm{B} 5 \mathrm{~N} 1$ & 436 & 666 & \multirow[b]{3}{*}{442} & \multirow[b]{3}{*}{775} \\
\hline $\mathrm{B} 5 \mathrm{~N} 2$ & 436 & 892 & & \\
\hline $\mathrm{B} 5 \mathrm{~N} 3$ & 454 & 767 & & \\
\hline BNS1 & 666 & 1,802 & \multirow[b]{3}{*}{825} & \multirow[b]{3}{*}{1,721} \\
\hline BNS2 & 1,021 & 1,739 & & \\
\hline BNS3 & 787 & 1,623 & & \\
\hline $\mathrm{B} 1 \mathrm{~S} 1$ & 758 & 1,656 & \multirow[b]{3}{*}{1,124} & \multirow[b]{3}{*}{1,834} \\
\hline $\mathrm{B} 1 \mathrm{~S} 2$ & 1,097 & 1,940 & & \\
\hline B1S3 & 1,518 & 1,908 & & \\
\hline B5S1 & 916 & 1,849 & \multirow[b]{3}{*}{1,110} & \multirow[b]{3}{*}{1,815} \\
\hline B5S2 & 1,325 & 1,831 & & \\
\hline B5S3 & 1,089 & 1,766 & & \\
\hline
\end{tabular}

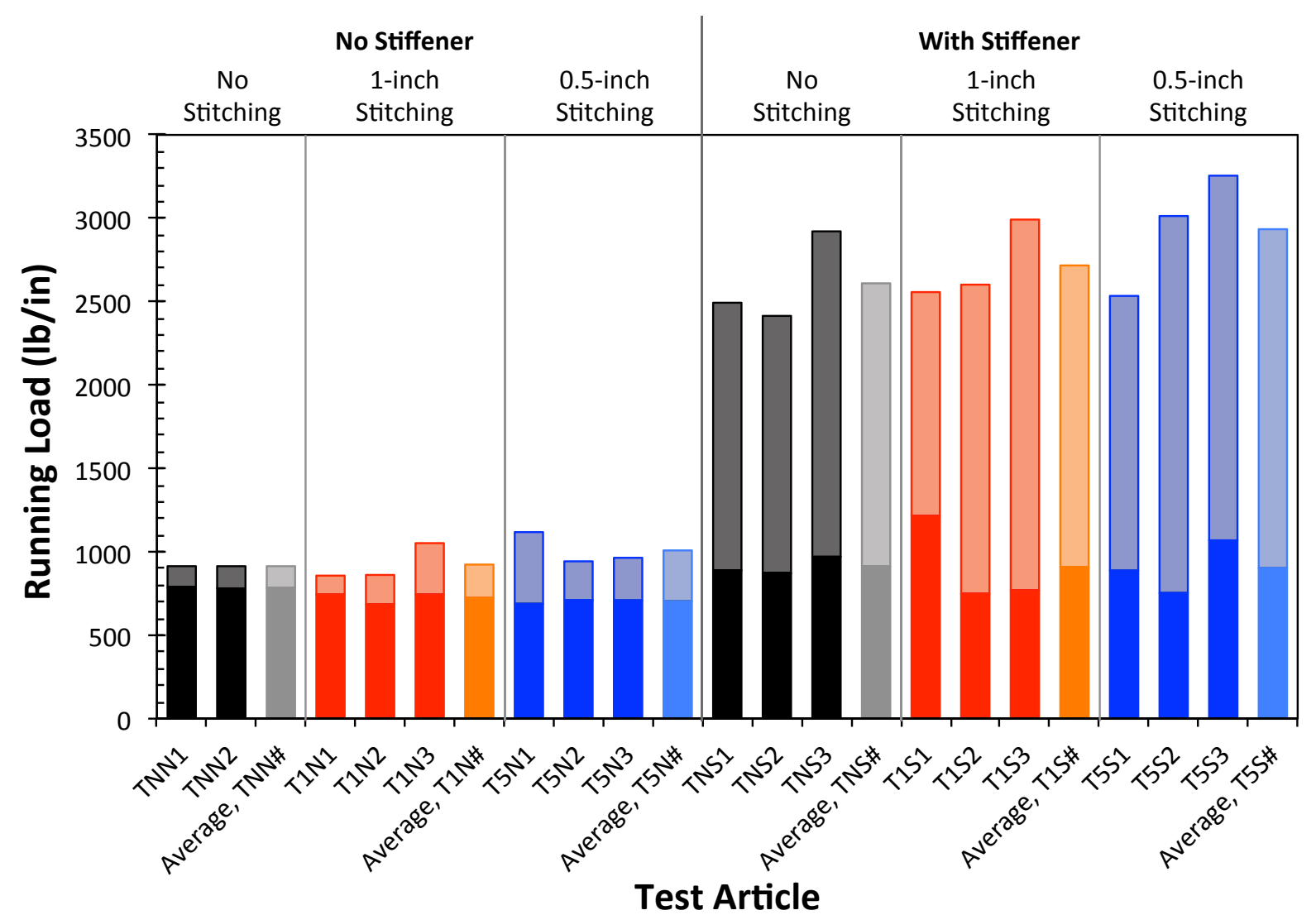

Figure 18. Running load, $\mathrm{N}_{\mathrm{x}}$, for tension test $\mathrm{T}$-cap test articles. 


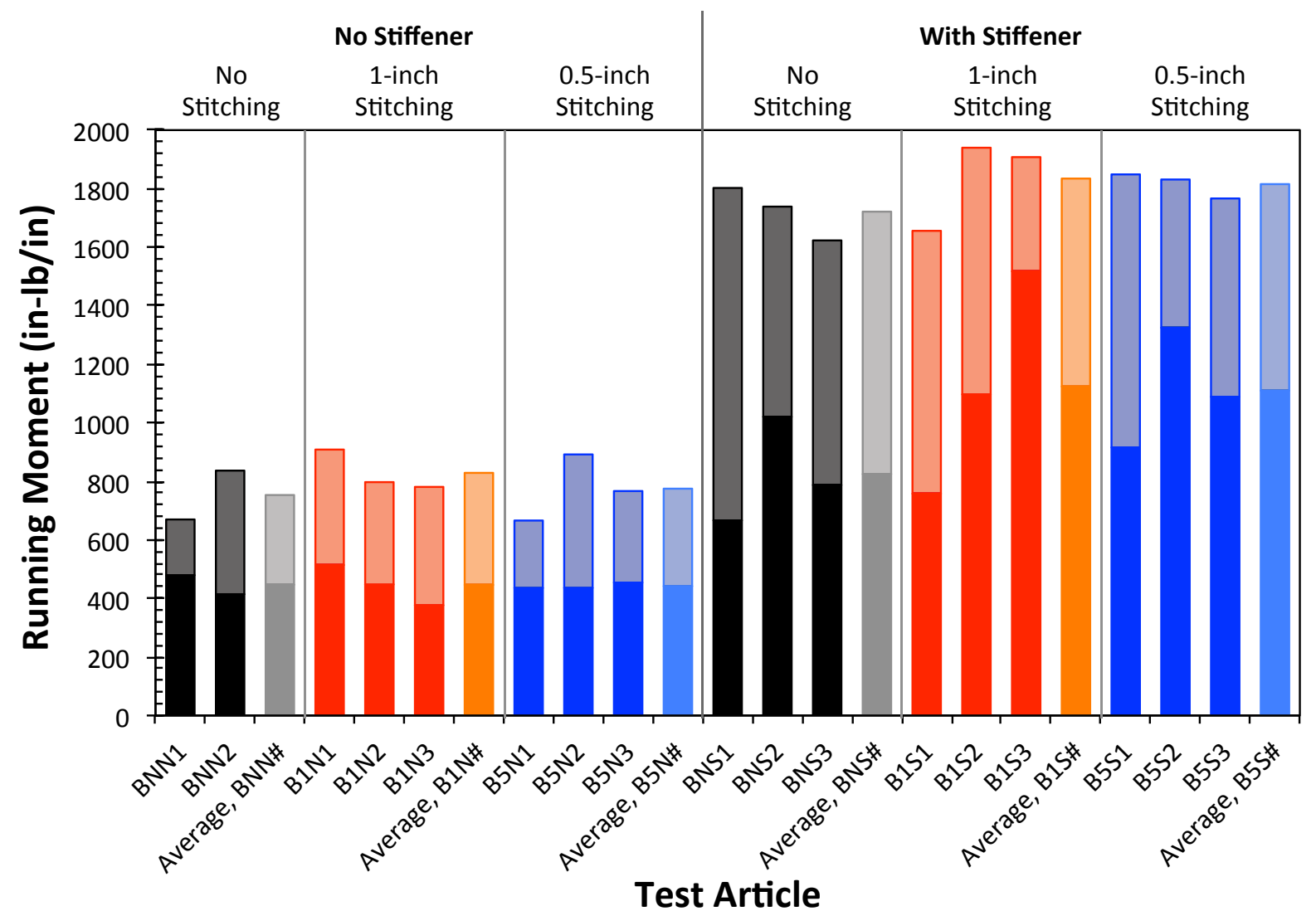

Figure 19. Running moment, $M_{x}$, for tension test $T$-cap test articles.

Table 6: Normalized average initial failure and average maximum loads.

\begin{tabular}{|c|c|c|c|}
\hline \multicolumn{4}{|c|}{ Tension Test Articles } \\
\hline \multicolumn{2}{|c|}{ Configuration } & \multirow{2}{*}{$\begin{array}{c}\text { Normalized Initial } \\
\text { Failure Load } \\
\end{array}$} & \multirow{2}{*}{$\begin{array}{c}\text { Normalized } \\
\text { Maximum Load }\end{array}$} \\
\hline Stiffener? & Web Stitch Spacing & & \\
\hline \multirow{3}{*}{ No } & None & 1.000 & 1.000 \\
\hline & 1.0 & 0.923 & 1.011 \\
\hline & 0.5 & 0.897 & 1.103 \\
\hline \multirow{3}{*}{ Yes } & None & 1.000 & 1.000 \\
\hline & 1.0 & 0.999 & 1.041 \\
\hline & 0.5 & 0.992 & 1.124 \\
\hline
\end{tabular}

\begin{tabular}{|c|c|c|c|}
\hline \multicolumn{4}{|c|}{ Bending Test Articles } \\
\hline Configuration & $\begin{array}{c}\text { Normalized Initial } \\
\text { Failure Load }\end{array}$ & $\begin{array}{c}\text { Normalized } \\
\text { Maximum Load }\end{array}$ \\
\hline \multirow{2}{*}{ Stiffener? } & Web Stitch Spacing & 1.000 & 1.000 \\
\cline { 2 - 4 } No & None & 0.998 & 1.101 \\
\cline { 2 - 4 } & 1.0 & 0.989 & 1.029 \\
\hline \multirow{3}{*}{ Yes } & 0.5 & 1.000 & 1.000 \\
\cline { 2 - 4 } & None & 1.363 & 1.066 \\
\cline { 2 - 4 } & 1.0 & 1.346 & 1.055 \\
\hline
\end{tabular}

18

American Institute of Aeronautics and Astronautics 
For test articles with no stiffener, the maximum attained load increases by $1.1 \%$ and $10.3 \%$ for the designs with 1-inch and 0.5 -inch stitch spacing in the T-cap web, respectively. However, the maximum load is not significantly higher than the initial failure load for these test articles. Additionally, the maximum load occurs after multiple load drops, and after significant damage has accumulated. For test articles with the stiffener present, the maximum attained load increases by $4.1 \%$ and $12.4 \%$ for the designs with 1 -inch and 0.5 -inch stitch spacing in the T-cap web, respectively. Also note that the maximum load for these test articles is significantly larger than the initial failure load, on the order of 2.5 to 3 times larger. After the initial failure occurs, the load typically continues to increase with small variations until a near maximum load was attained prior to noticeable load drop. The maximum load for these test articles typically occurs later in the test, but is usually not significantly larger than the load obtained at the end of the initial rise of the load versus displacement curve that is prior to the first significant load drop (see Fig. 17). The continued load increase, and the significant increase in maximum load compared to the initial failure load, may be a result of a mechanical connection that is formed by the stringer and the keyhole in the T-cap through which the stringer passes. This connection permits the T-cap web to transfer load into the stringer, which then passes load into the surrounding skin, rather than all the load having to pass through the base of the T-cap web as is the case for the stringerless test articles. This is borne out by the delaminations at the base of the stringer web as shown in Fig. 20, which clearly indicates a load path through the stringer and into the skin region. Lastly, because of the presence of the keyhole that separates the base of the web on either side of a stringer, delaminations in the base of the stringer don't necessarily occur at the same load on either side of the stringer as this separation arrests the delamination due to the discontinuity. When a stringer is not present, the delamination is free to grow across the complete width of the test article and thus the DIC identified the origination of the delamination at nearly the same load on both sides. This phenomenon applies to both the tension and bending tests. Note that the presence of the stiffener increased the initial and maximum tension failure loads by about $16 \%$ and $200 \%$, respectively, compared to the stiffenerless baseline test article. This increase can likely be attributed to the web pulling up on the stringer during loading through the mechanical connection of the keyhole enveloping the stringer, which provided load distribution away from the fillet region of the web and flange interface. This type of behavior would not be seen for the tension loading if the stiffener were a blade configuration, for example, so this type of load redistribution is dependent on the design of the stringer.

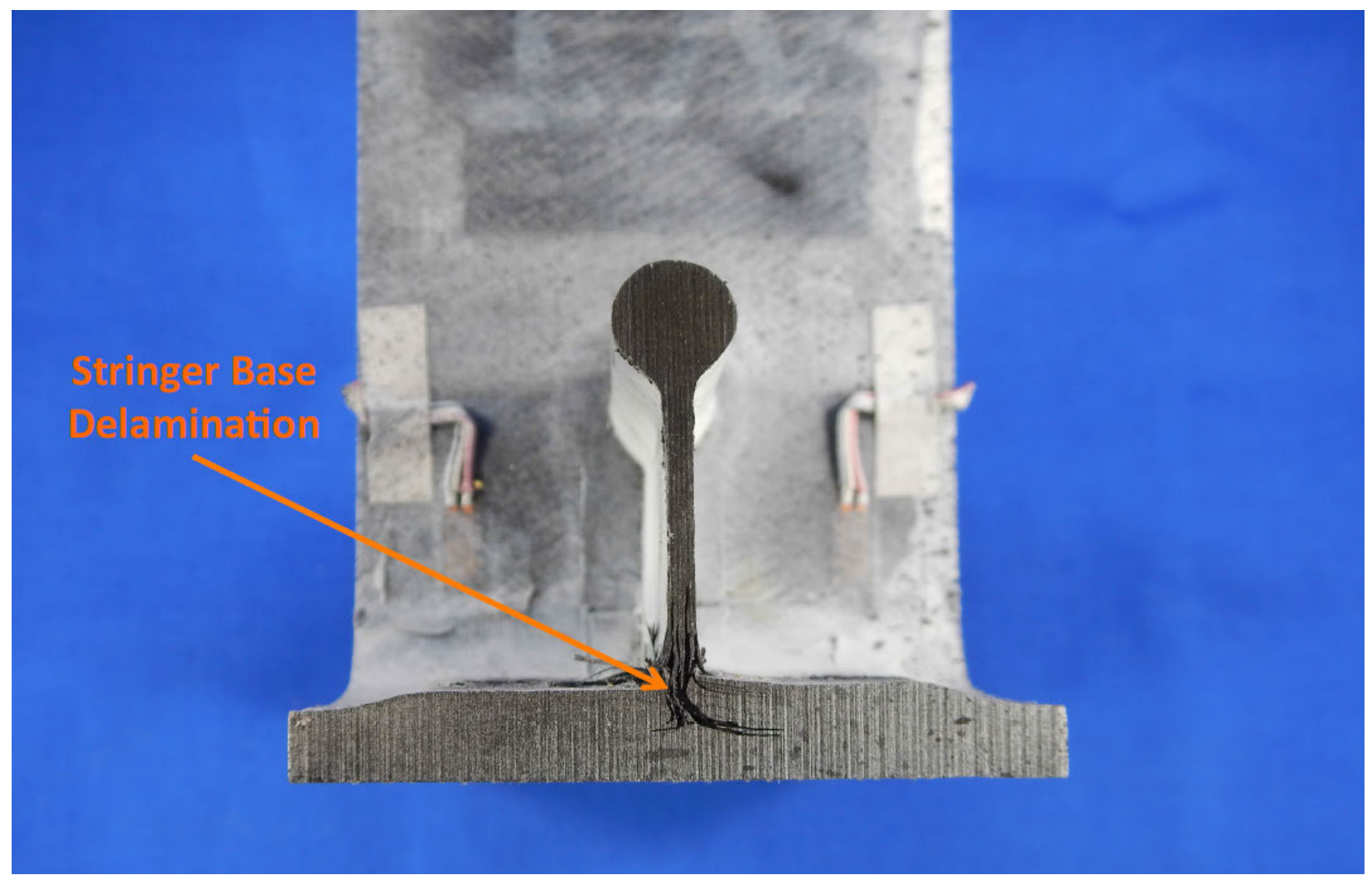

Figure 20. Delaminations at the stringer base observed in test article TNS1. 
For the bending test articles, it is seen that the initial failure load for bending is relatively unaffected by the additional T-cap web stitching for test articles without a stiffener. The average initial failure bending moment errors for these test articles were less than $2.0 \%$. Initial failures developed as a delamination at the noodle region of the web and flange intersection on the tension, interior, side of the web. The maximum bending moment occurs prior to the final bending moment drop, and was the result of crippling of the outer plies on the compression, exterior, side of the web in the vicinity of the stitch row at the top of the fillet region. The stitch row at this crippling failure location is the stitch row at the web base fillet associated with normal assembly of the PRSEUS structure. For test articles with a stiffener present, the initial failure bending moment increased by $36.3 \%$ and $34.6 \%$ for the designs with 1 -inch and 0.5 -inch stitch spacing in the T-cap web, respectively. This is a significant increase over the test articles without the additional stitching. Initial failures developed in the same manner as those without the stiffener and occurred in the interior (tension side) radius near the noodle. The maximum bending moment was reached just prior to crippling failure on the compression side of the web at the height of the stiffener, which is higher up the web than the crippling observed in the test articles without the stiffener. Figs. 21 and 22 show the crippling failure on for the representative test articles with and without a stringer, respectively. The maximum attained load increased with increased stitching in the T-cap web. For test articles without a stiffener, the maximum attained load increases by $10.1 \%$ and $2.9 \%$ for the designs with 1 -inch and 0.5 -inch stitch spacing in the T-cap web, respectively. For test articles with a stiffener present, the maximum attained load increases by $6.6 \%$ and $5.5 \%$ for the designs with 1-inch and 0.5 -inch stitch spacing in the T-cap web, respectively. It is likely that bearing of the T-cap web on the top of the stringer resulted in the higher bending moment at initial failure as the load was carried in the stringer rather than in bending of the web. This is also likely the cause of the relocation of the crippling area that developed at maximum load. Note that the presence of the stiffener increased the initial and maximum bending failure loads by about 85 $150 \%$ and $129-142 \%$, respectively, compared to the stiffenerless baseline test article. This significant increase can likely be attributed to the web bearing on the stringer during loading, which provided load distribution away from the fillet region of the web and flange interface. This type of behavior is likely to occur regardless of the stringer design.

Lastly, one of the objectives of the testing was to provide data for analysis validation. While time did not permit analysis validation to be performed and presented in this paper, a discussion of the type of data available in Ref. 17 is provided herein to give some insight into possible validation techniques. As previously mentioned, the data in the reference only include strain contour plots for one of each type of test article design, however, contour data are

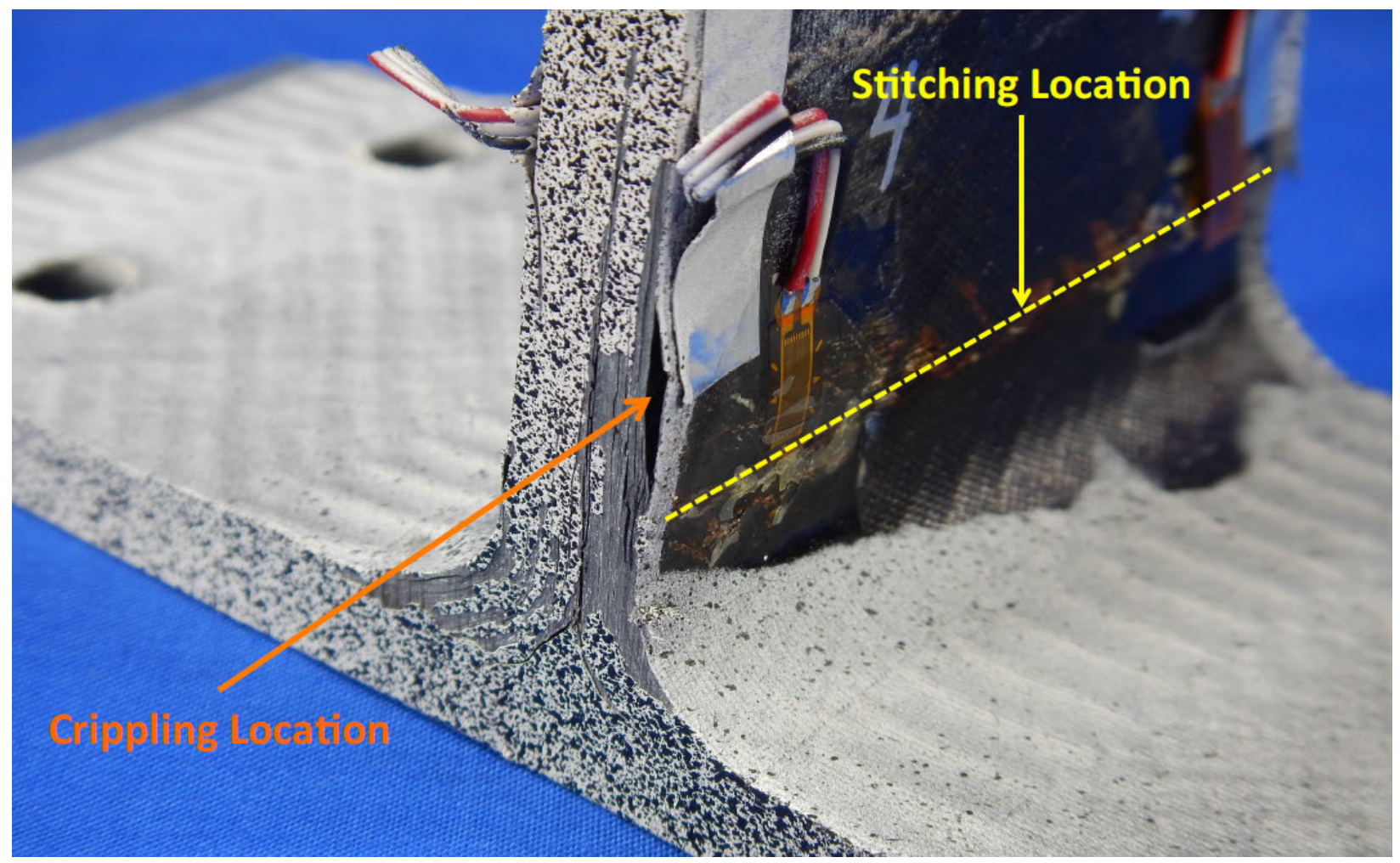

Figure 21. Crippling resulting from maximum load observed in test article B1N1.

American Institute of Aeronautics and Astronautics 


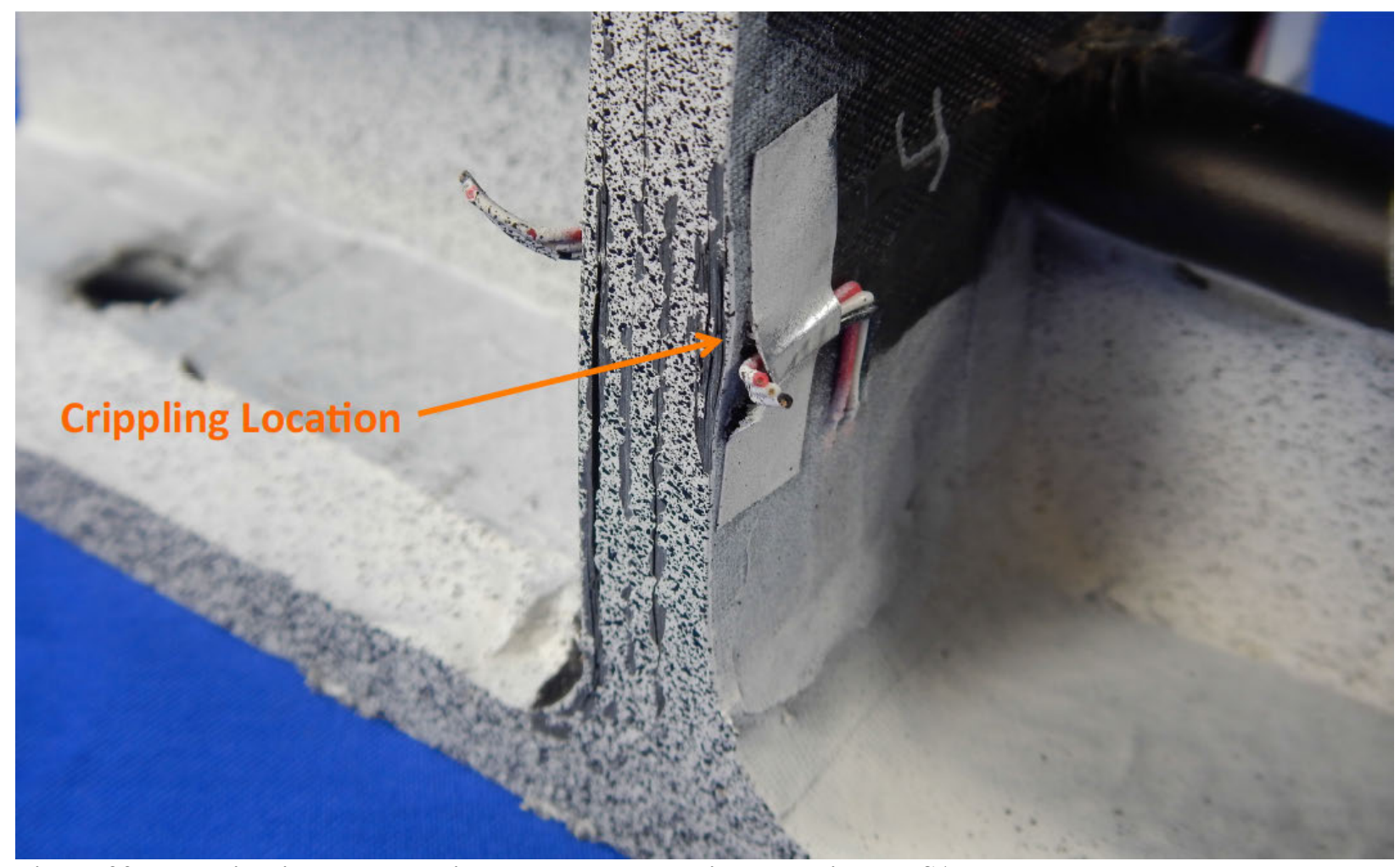

Figure 22. Delaminations at the stringer base observed in test article BNS1.

archived for all test articles. An initial examination of the data shows that a plot of maximum principal strain is a good indicator that a delamination has developed, and may also be a good indicator that the delamination is about to develop. Maximum principal strain plots before and after the initial delamination failure for test article TNN1, as recorded by the 5 MP local DIC system, are shown in Figs. 23 and 24. In Fig. 23, there are a couple of possible regions that indicate where the initiation may occur at a maximum principal strain level of approximately 0.004 in/in, with the most likely one being the slightly larger region of light orange as indicated on the figure. Small areas at the edge of the DIC processing area that are at the strain scale limits are spurious values that may ocassionally occur due to various factors in the image processing, such as the presence of stitch fiber tufts or some other imperfection.

Figure 24 shows that the initial delamination failure did actually occur and pass through the region indicated on Fig. 23 as the most likely failure location. While reported as a maximum principal strain in Fig. 24, in the vicinity around the delamination crack, these are actually fictitious strain values, as it is really a measure of the gap separation rather than an actual strain measure within the material itself. A close-up image of the TNN1 delamination is shown in Fig. 25. The dashed yellow line in the figure shows the approximate location of the delamination crack, which is difficult to see with the eye, but was easily detected by DIC. While the delamination passed the stitch line at the top of the web base radii, as seen in Fig. 24, it was observed that the stitching did prevent significant further delamination growth until the failure of the stitching that occurred at the maximum load. It should also be noted that while for TNN1, the initial delamination occurred at the major failure surface that developed at the maximum load, this was not always the case. Additionally, the major failure surface was uniformly located at the interfaces of the inner and outer flange stacks with each other, the noodle region and the skin stacks, which are identified by the red lines in Fig. 6 . 


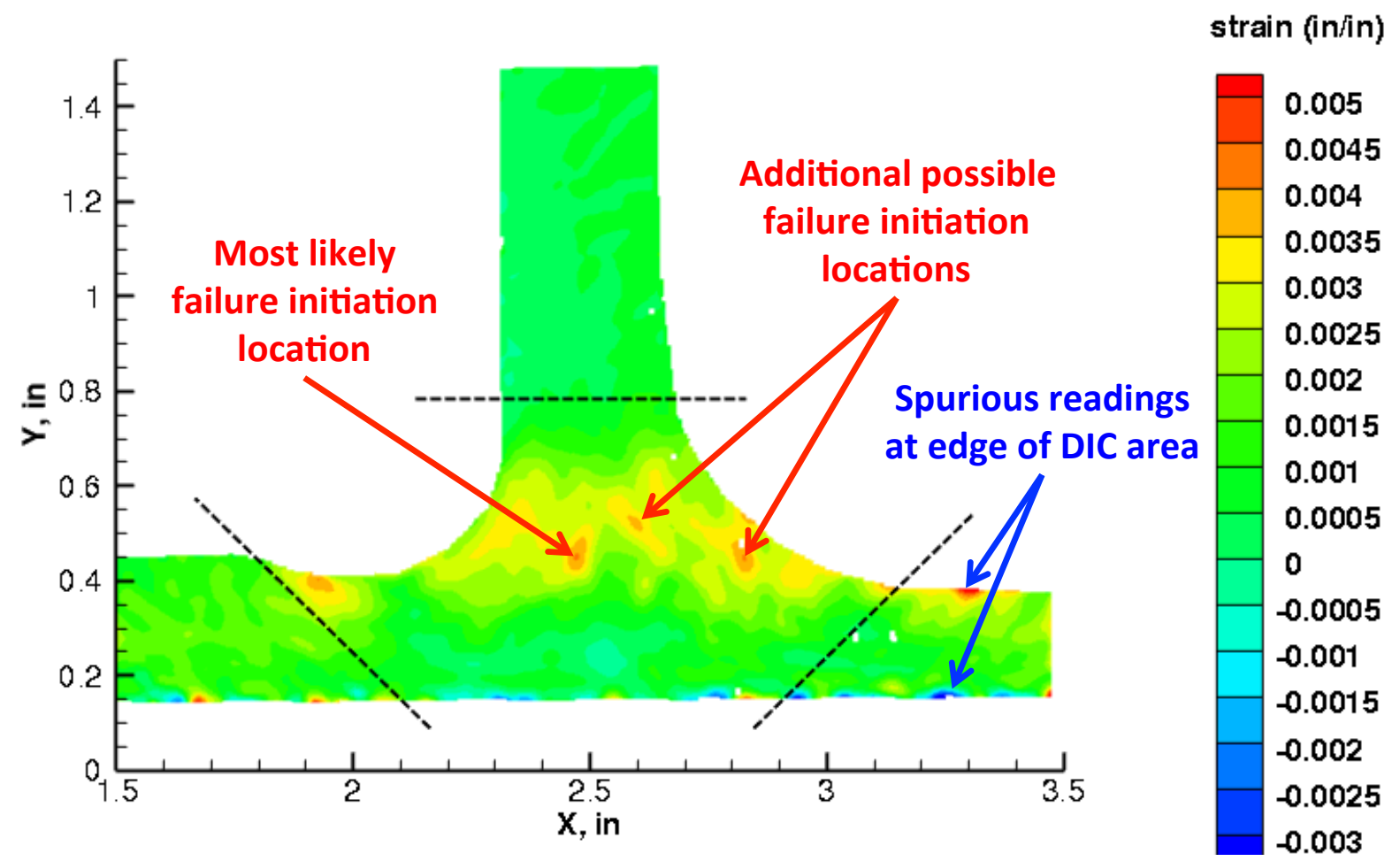

Figure 23. Maximum principal strain in test article TNN1 from 5 MP local DIC system just prior to initial delamination failure.

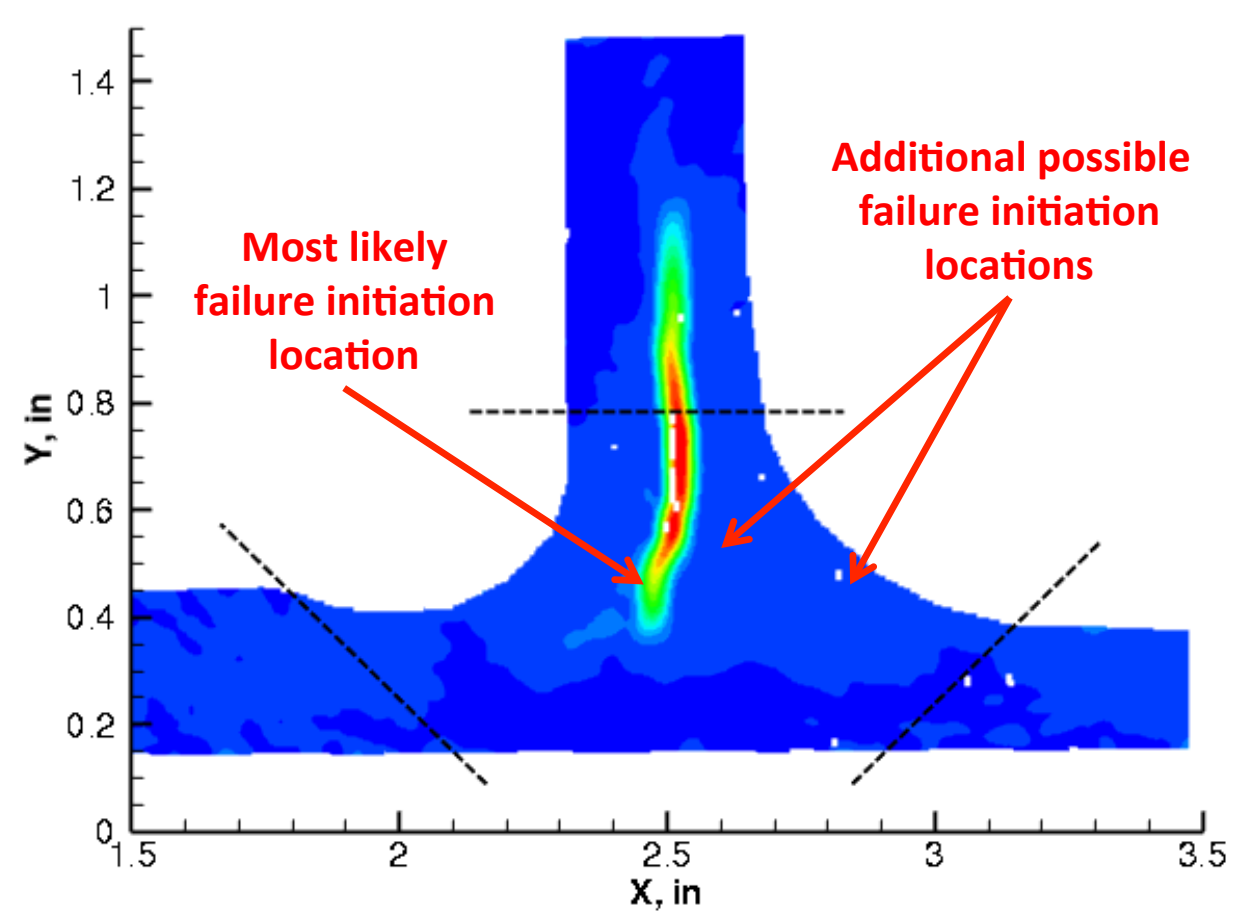

strain, in/in

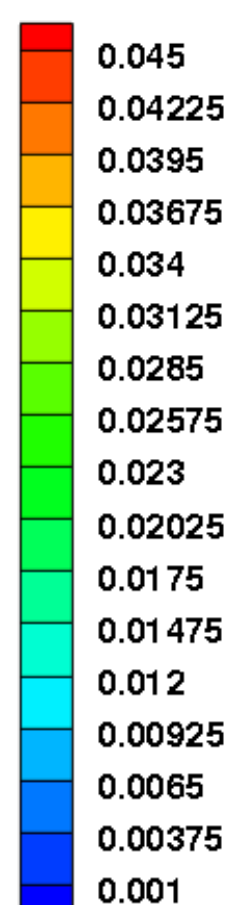

Figure 24. Maximum principal strain in test article TNN1 from 5 MP local DIC system just after initial delamination failure. 


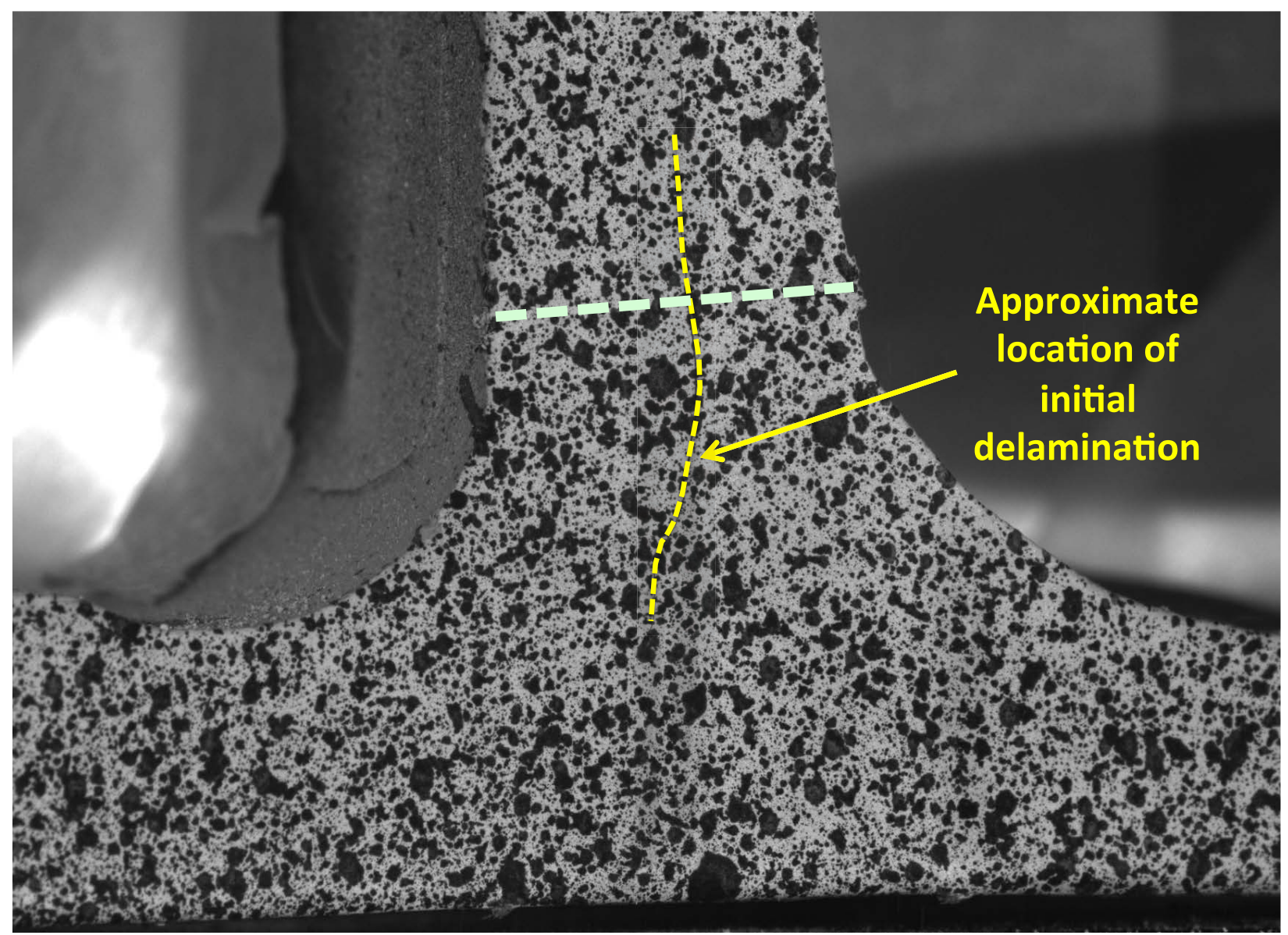

Figure 25. Image of initial delamination failure location in test article TNN1 from 5 MP local DIC system.

\section{Conclusions}

A series of tests were conducted on a variety of T-cap integral caps that are similar to what was used for assembly of the PRSEUS MBB. These test articles were cut from an alternate keel, and included test articles with and without a stiffener passing through the web. Additionally, three designs were tested, including the original design that had no additional stitching along the length of the web, one that had additional stitching at 1-inch increments, and one that had additional stitching at 0.5 -inch increments. Test articles were tested in either tensiononly or bending-only loading. There were three test articles for each configuration and design combination and load condition, except there were two test articles for those without a stringer and without additional stitching.

Test data were presented and discussed, leading to a number of observations, which are as follows:

- Presence of the additional web stitching:

- Decreased the initial failure load for tension-only tests for test articles without a stiffener. There was no significant difference in the initial failure loads for the tension-only test articles with a stiffener present, with only a slight reduction in initial failure load observed.

- Increased the maximum load attained for all test articles, however, those without a stiffener and with 1-inch stitch spacing exhibited minimal improvement.

- Showed no significant difference on the initial failure bending moment for bending-only tests for test articles without a stiffener. However, there was a significant increase in the initial failure bending moment for test articles with a stiffener present.

- Stitching increased the maximum bending moment attained for all test articles.

- The presence of the stiffener:

0 Increased the initial and maximum tension failure loads compared to the stiffenerless baseline test article. This increase can likely be attributed to the web pulling up on the stringer during loading through a mechanical connection, which provided load distribution away from the 
fillet region of the web and flange interface, a type of behavior that would not be seen if the stiffener were a blade configuration, for example, so this type of load redistribution is dependent upon the design of the stringer.

- Increased the initial and maximum bending failure loads significantly, compared to the stiffenerless baseline test article. This increase can likely be attributed to the web bearing on the stringer during loading, which provided load distribution away from the fillet region of the web and flange interface. This type of behavior is likely to occur regardless of the stringer design.

- Initial delaminations occurred anywhere within the web thickness, and did not always coincide with an interface of the flange stacks, noodle or skin stacks.

- The major delamination surfaces associated with the maximum load were located along the interfaces of the stack groupings and noodle region, although many delaminations were present throughout the thickness of the web.

Based on these observations, combined with the small sample size for each configuration, it is not clear that additional stitching along the height of the T-cap web is beneficial in terms of failure at the T-cap web and skin interface. Consider that the testing that was completed was under tension-only or bending-only, while in service, these webs will see a combination of tension and bending due to the presence of internal pressure. Tension and bending loads appear to have opposing effects on the response, so combined loading may have competing effects on the response. Additionally, since design will likely be driven by the initial failure load, the current testing shows that the original design is slightly superior to the two designs with additional stitching along the height of the web because loads for the baseline design are higher than or similar to the new designs. Stitching did show some benefit in maximum load, so for damage tolerance purposes it may be desirable to include the additional stitching and accept slightly diminished initial failure loads. Also, the presence of the stiffener in the test article had a large effect on the failure loads, but the extent of that effect is likely hightly dependent on the type of stiffener for the tension test articles. Lastly, there may be other damage tolerance reasons to include the additional stitching, but if it is desirable to maximize the initial failure load, it would be advisable to have the first row of stitching in the web as far from the fillet stitch as possible.

\section{Acknowledgements}

The authors would like to acknowledge the contributions of Diane Griffin and George Cowley for setting-up and performing the tension and bending T-cap tests, respectively. The authors would also like to acknowledge Nathaniel Gardner, Michael McNeill and David Dawicke for setting-up and performing the optical measurements, and collecting and analyzing the data.

\section{References}

${ }^{1}$ Velicki, A., "Damage Arresting Composites for Shaped Vehicles, Phase I Final Report," NASA CR-2009-215932, September, 2009.

${ }^{2}$ Velicki, A., and Hansen, D., "Novel Blended Wing Body Structural Concepts," NRA-03-LaRC-02 Maturation for Advanced Aerodynamic and Structures Technologies for Subsonic Transport Aircraft: Phase I Final Report, July 13, 2004.

${ }^{3}$ Hoffman, K., Air Vehicle Technology Integration Program (AVTIP), Delivery Order 0059: Multi-role Bomber Structural Analysis, AFRL-VA-WP-TR-2006-3067, May 2006, Final Report for December 14, 2004 - May 8, 2006.

${ }^{4}$ Karal, M., "AST Composite Wing Study - Executive Summary," NASA/CR-2001-210650, Prepared for NASA, Langley Research Center under Contract NAS1-20546, March, 2001.

${ }^{5}$ Velicki, A. and Thrash, P. J., "Advanced Structural Concept Development Using Stitched Composites," AIAA Paper 20082329, 49th AIAA/ASME/ASCE/AHS/ASC Structures, Structural Dynamics, and Materials Conference, April 7-10, 2008, Schaumburg, IL.

${ }^{6}$ Lovejoy, A. E., "PRSEUS Pressure Cube Test Data and Response," NASA/TM-2013-217795, May, 2013.

${ }^{7}$ Yovanov, N., Lovejoy, A., Baraja, J., and Gould, K., "Design, Analysis and Testing of a PRSEUS Pressure Cube to Investigate Assembly Joints," 2012 Airworthiness \& Sustainment Conference, Baltimore, Maryland, April 2-5, 2012.

${ }^{8}$ Rouse, M., "Methodologies for Combined Loads Tests Using a Multi-Actuator Test Machine," presented at the Society for Experimental Mechanics meeting, June, 2013.

${ }^{9}$ Rouse, M., and Jegley, D., "Preparation for Testing a Multi-Bay Box Subjected to Combined Loads," presented at the Society for Experimental Mechanics meeting, June, 2015.

${ }^{10}$ Ayale, A. and Thrash, P., "AST Composite Wing Program: Semi-Span Wing Fabrication Tests and Supporting Technology," Final Report for NASA Contract NASl-20546, Long Beach, CA, 2000.

${ }^{11}$ Moon, D. and Velicki, A., "AST Composite Wing Program: Full-Scale Stitched/Resin Film Infused Wing Design, Fabrication and Structural Verification," Final Report for NASA Contract NAS1-20546, Long Beach, CA, 2000. 
${ }^{12}$ Jegley, D. C., Bush, H. G., and Lovejoy, A. E., "Structural Response and Failure of a Full-Scale Stitched Graphite-Epoxy Wing," Journal of Aircraft, Vol. 40, No. 6, November-December, 2003, pp. 1192-1199.

${ }^{13}$ Johnston, P. H., "Ultrasonic Nondestructive Evaluation of PRSEUS Pressure Cube Article in Support of Load Test to Failure," NASA/TM-2013-217799, May, 2013.

${ }^{14}$ Velicki, A., Hoffman, K., Linton, K., Thrash, P., Pickell, R., and Turley, R., "Fabrication of Lower Section and Upper Forward Bulkhead Panels of the Multi-Bay Box and Panel Preparation," NASA/CR-2015-218981, NASA Langley Research Center, Hampton, VA, November, 2015

${ }^{15}$ Leone, F. A., Jegley, D.C., "Compressive Testing of PRSEUS Frame and Stringer Alternate Configurations," NASA/TM2016-218974, NASA Langley Research Center, Hampton, VA, 2016.

${ }^{16}$ Leone, F. A., "Pultruded Rod/Overwrap Testing for Various PRSEUS Stringer Configurations," NASA/TM-2016-218975, NASA Langley Research Center, Hampton, VA, 2016.

${ }^{17}$ Lovejoy, A. E., and Leone, F. A., "T-Cap Pull-Off and Bending Behavior for Stitched Structure," NASA/TM-2016-218971, NASA Langley Research Center, Hampton, VA, 2016.

${ }^{18} \mathrm{https}: / / \mathrm{www}$. alliedvision.com.

${ }^{19} \mathrm{http}: / /$ www.ptgrey.com.

${ }^{20} \mathrm{http}: / / \mathrm{www}$. correlatedsolutions.com. 